\title{
O livro do conhecimento: um serious game educacional para aprendizagem de ortografia da Língua Portuguesa
}

\author{
Title: "O Livro do Conhecimento": a serious educational game for learning Portuguese \\ orthography
}

\author{
Fernanda Pires \\ Universidade do Estado do \\ Amazonas - UEA \\ fpires@uea.edu.br \\ Joao Ricardo Serique Bernardo \\ Universidade do Estado do \\ Amazonas - UEA \\ jrsbr.lic16@uea.edu.br
}

\author{
Marcela Pessoa \\ Universidade do Estado do \\ Amazonas - UEA \\ msppessoa@uea.edu.br \\ Rafaela Melo Ferreira \\ Universidade do Estado do \\ Amazonas - UEA \\ rmf.lic16@uea.edu.br
}

\author{
Fabio Michel Maquiné de Lima \\ Universidade do Estado do \\ Amazonas - UEA \\ fmmdl.lic16@uea.edu.br
}

\begin{abstract}
Resumo
O impacto que os jogos educacionais podem causar nos processos de aprendizagem tem sido uma importante questão de pesquisa. Este artigo apresenta um jogo educacional de aventuras intitulado "O Livro do Conhecimento", cuja finalidade é promover o exercício da ortografia em Língua Portuguesa de forma lúdica, motivando os jogadores através dos desafios propostos. O software foi desenvolvido seguindo etapas que consideraram os aspectos educacionais pedagógicos, o sistema biológico de processamento da informação e os requisitos de jogos comerciais e educacionais. O jogo está fundamentado na Teoria Cognitiva da Aprendizagem Multimídia (TCAM) e em processos de aprendizagem ativa, no que tange o desenvolvimento da interface e fluxo de aprendizagem. A análise dos testes $e$ avaliações realizados apontam a existência impactos positivos, no sentido de possibilitar que a aprendizagem de estruturas e regras ortográficas em Língua Portuguesa seja potencializada.
\end{abstract}

Palavras-Chave: Aprendizagem ativa, ortografia em Língua Portuguesa, jogos de propósito sério, narrativas, teoria cognitiva de aprendizagem multimídia.

\begin{abstract}
The impact that educational games can have on learning processes has been an important research issue. This paper presents an educational adventure game entitled "The Book of Knowledge", which proposes to promote the exercise of Portuguese spelling in a playful way, motivating the players through the proposed challenges. The software was developed through steps that considered the pedagogical educational aspects, the biological information processing system and the requirements of commercial and educational games. The game is based on the Cognitive Theory of Multimedia Learning (TCAM) and on active learning processes, regarding the development of the interface and learning flow. The analysis of the tests and evaluations indicated the existence of positive impacts, in order to enable the learning of structures and orthographic rules in Portuguese language to be enhanced.

Keywords: active learning, spelling in Portuguese, serious games, storytelling, cognitive theory of multimedia learning.
\end{abstract}

Cite as: Pires, F., Pessoa, M., de Lima, F. M. M., Bernardo, J. R. S.\& Ferreira, R. M. (2020). "O Livro do Conhecimento": a serious educational game for learning Portuguese (O livro do conhecimento: um serious game educacional para aprendizagem de ortografia da Língua Portuguesa). Brazilian Journal of Computers in Education (Revista Brasileira de Informática na Educação - RBIE), 28, 436-460. DOI: 10.5753/RBIE.2020.28.0.436 


\section{Introdução}

Pesquisas vêm sendo realizadas com a finalidade de unir aprendizagem e diversão, por meio de jogos eletrônicos (Klopfer et al., 2018), com o objetivo de alcançar o engajamento empregado nos jogos para entretenimento também naqueles cujo foco é a promoção da aprendizagem. McGonigal (2017) concluiu que o mesmo engajamento registrado por meio da participação de jogos on-line ao redor do mundo, poderia ser usado para ajudar a resolver problemas do mundo real, bem como promover aprendizagem formal em ambientes não formais.

Investigações têm se concentrado em discutir os fatores que possam fazer com que um jogo alcance sucesso e quais são os elementos responsáveis por divertir e engajar os jogadores (Gee, 2003; Rogers, 2014). O que se busca é identificar as razões que geram engajamento de forma a conquistar fãs em diversas as áreas e prenda a atenção buscando manter pessoas, por maior período, jogando e se sentindo cada vez mais inseridas no jogo, como se fizessem parte dele.

Defende-se ainda que é possível aprender com os jogos, uma vez que são criadas novas conexões neurais à medida em que a solução é proposta para resolver um enigma (Gee, 2003; Huizinga, 2014; Rogers, 2014). Desta forma, alguns jogos direcionam a aprendizagem aos conteúdos presentes nos componentes curriculares e são conhecidos como Jogos Educacionais, Serious Game, Learning Games ou Ressonant Games (Hainey et al., 2016; Klopfer et al., 2018; Rosenheck et al., 2016) e, apesar das inúmeras denominações, o principal objetivo destes é oferecer uma proposta lúdica de aprendizagem em formato de jogo.

O grande desafio desta área é criar jogos de propósito sério de tal forma que não percam as características que provocam a imersão e o consequente engajamento do usuário. Os serious games foram discutidos como uma alternativa eficiente, capaz de movimentar milhões de dólares, sobretudo com aplicações empresariais e militares (Susi et al., 2007). Mais recentemente, a academia e a indústria deixaram de discutir a importância dos serious games e focaram em como conciliar os atributos educacionais com os requisitos presentes em jogos comerciais para, desta forma, obter bons resultados, através de um espaço imersivo e não somente um ambiente de aprendizagem gamificado (Bellotti et al., 2013). Recentemente Klopfer (2018), do Arcade Educational do MIT, compartilhou algumas de suas experiências em busca da justa medida de como prover vivências engajadoras através de jogos que possam ser incorporadas às atividades de sala de aula, em uma perspectiva curricular. Neste sentido, este artigo, ao tratar de um serious game educacional, apresenta o seu processo de concepção, ideação, prototipação e desenvolvimento do jogo que tem como objetivo explorar um dos componentes curriculares de Língua Portuguesa, em um cenário que apresenta um problema do mundo real no que diz respeito aos processos de letramento.

A escolha do componente curricular se deu em função dos números que vêm sendo apresentados nos últimos anos. A Avaliação Nacional de Alfabetização (ANA) revelou que 34,46\% dos brasileiros não possuem rendimento considerado adequado na escrita (INEP, 2016). Os números são preocupantes, pois sugerem que a base nacional da educação passa por dificuldades. Este problema parece persistir até o final do Ensino Médio como evidenciado pelo Exame Nacional do Ensino Médio (ENEM), aplicado no ano de 2017, que dos 4.714.558 milhões de participantes apenas 53 obtiveram a nota máxima na prova de redação, o que representa $0,001 \%$ do total de alunos presentes. Além disso, 309.157, cerca de 6,5\% dos participantes, zeraram na prova de redação. Em 2018, dados do Índice Nacional de Analfabetismo Funcional (INAF) revelaram que, entre os brasileiros, a taxa de analfabetismo funcional (dificuldade de leitura e escrita em atividades cotidianas) é de $29 \%$ e que $8 \%$ da população brasileira é classificada como analfabeta (não sabem ler e escrever). Os recentes dados negativos mobilizaram vários pesquisadores a discutir como desenvolver metodologias que possam auxiliar na aprendizagem da Língua Portuguesa (Lorensatti, 2009; A. C. C. d. Oliveira et al., 2017; Yamato et al., 2017). 
Mediante o cenário descrito, este artigo apresenta um serious game educacional de açãoaventura, em estilo plataforma, para desktop, tendo como público-alvo direto estudantes do Ensino Fundamental II e Ensino Médio. O jogo, intitulado "O Livro do Conhecimento", tem como finalidade auxiliar na aprendizagem de Língua Portuguesa, com foco nas habilidades ortográficas da escrita e utilização das palavras. Seu desenvolvimento levou em consideração os requisitos cognitivos de aprendizagem, os fatores de Interação Humano-Computador (IHC) e a importância da narrativa enquanto processo de consolidação de memórias de longo prazo. A mecânica do jogo proposto apresenta elementos de exploração, aventura, progressão do herói e combates, levando o jogador a um processo de imersão, em que se espera, que sejam consolidadas as memórias de longo prazo, para que ocorra a aprendizagem. Apresentam-se, como cenário de uso, os espaços de educação formal e não formal, podendo ser utilizado em sala de aula, como medida de reforço escolar ou por pessoas interessadas em fixar o conteúdo.

Este artigo está organizado da seguinte forma: na Seção 2 são descritos conceitos sobre jogos eletrônicos, cognição e processo de aprendizagem em ambientes digitais, na Seção 3 são apresentados os trabalhos relacionados; A Seção 4, descreve as etapas do desenvolvimento do jogo, incluindo cenário e ambiente de desenvolvimento. Na Seção 5 são apresentados os resultados, a avaliações de usabilidade e discussões sobre os resultados e na Seção 6 são apresentadas as considerações finais.

\section{Jogos eletrônicos e processos cognitivos de aprendizagem}

Huizinga (2014) descreve jogos como uma atividade voluntária do ser humano, por se tratar de algo lúdico, divertido e cômico, sendo sua existência anterior à cultura. Jogos eletrônicos são aqueles que podem ser acompanhados via tela de vídeo e têm sua origem no ano de 1952, quando os computadores existiam somente nos grandes centros de pesquisa e suas telas de exibição eram osciloscópios (Rogers, 2014). Com a evolução das tecnologias eles puderam chegar às casas das pessoas através dos consoles, árcades e jogos de computador. Têm alcançado um número cada vez maior de pessoas que despendem horas engajadas em missões virtuais, criando relações interpessoais entre os seu avatares, salvando pessoas, vencendo guerras, entre outros (McGonigal, 2017).

Os jogos vêm sendo defendidos como alternativas lúdicas com o propósito de aprendizagem, como evolução a este conceito, existem os serious games educacionais, cujo objetivo é a promoção da aprendizagem dirigida. Segundo Abt (1987), serious games são aqueles cujo objetivo principal não é o entretenimento e sim a aprendizagem de forma lúdica, onde o planejamento se concentra nos objetivos de aprendizagem. Zyda (2005) afirma que as principais diferenças entre um serious game e um jogo comercial estão relacionadas a aspectos pedagógicos que permitem a transmissão do conhecimento e o desenvolvimento de habilidades. Porém, esses aspectos não devem se sobrepor aos aspectos comuns dos jogos tradicionais que dizem respeito à diversão, motivação, imersão e engajamento.

Para Michael e Chen (2005), os serious games possuem um universo próprio, que pode ter ou não relação com o mundo real, objetivando gerar imersão ao usuário. Um dos benefícios da utilização de serious games na educação é a possibilidade de vivenciar situações do mundo real, que não seriam possíveis devido a questões de segurança ou de custo, por exemplo. Entre os desafios que a área apresenta, destaque para a questão de como criar uma gameplay capaz de gerar imersão e posterior engajamento em serious games, neste contexto, uma das áreas que tem se sobressaído é a neurociência, por mapear o cérebro humano e suas funções (Gee, 2003; Klopfer et al., 2018) 
Conforme Mitchell e Savill-Smith (2004), os jogos podem potencializar o desenvolvimento de habilidades analíticas, espaciais, estratégicas, de memorização, de atenção e até mesmo insight. Além disso, podem melhorar as habilidades de reconhecimento e a resolução de problemas, tomadas de decisão, colaboratividade, entre outros. Possui potencial de melhorar a integração da memória de curto com a de longo prazo pelas experiências através dos multiversos presentes nos jogos e as emoções que despertam. Pesquisadores têm discutido os jogos como ferramentas capazes de auxiliar no processo de aprendizagem (Kafai e Burke, 2015; Subrahmanyam e Renukarya, 2015). Nesses ambientes lúdicos existe um processo de imersão em que o usuário se despe de sua identidade e seu foco passa a ser a jornada do herói digital.

Por outro lado, aprender a comunicar-se através da fala e da escrita é uma habilidade construída por uma rede simbólica de significados cuja configuração existe no sistema central de regras de um idioma (Carraher, 2012). Lorensatti (2009) reforça que a aprendizagem da Língua Portuguesa é essencial no processo de comunicação oral ou escrita, além do que, a língua é o que define uma nação. Posto isto, o Livro do Conhecimento, descrito neste artigo, é um serious game, que tem como objetivo auxiliar no processo de aprendizagem de Língua Portuguesa, desenvolvido para desktop. É classificado como um jogo de plataforma aventura-ação, definido por Rogers (2014) como aqueles que envolvem puzzles e têm objetivos baseados em histórias cujo cenário é formado por plataformas que permitem ao personagem principal andar, pular ou quicar em busca de seu alvo.

Projetar um jogo, necessita da compreensão dos processos cognitivos humanos, especialmente em como ocorre a interação da percepção, atenção e memória, como funcionam as emoções e no caso dos serious games, como funciona a estrutura de criação e memórias de longo prazo para gerar aprendizagem significativa.

\subsection{Cognição e Processo de aprendizagem em ambientes digitais}

Miller (1956) começou a revolução nos estudos de processo de aprendizagem ao provar que a memória de trabalho (curta duração) está limitada a processar entre $7 \pm 2$ informações (chunk) concorrentemente. Já na década de 1970 tem-se os primeiros passos da Teria da Dupla Codificação de Allan Paivio, que defende que o cérebro humano possui dois canais diferentes para processamento da informação, o visual e o auditivo (Clark e Paivio, 1991). O estudo no campo biológico vem até a Teoria da Carga Cognitiva, que defende a existência de uma limitação na memória de trabalho. Existe um número determinado de informações que a memória de curta duração é capaz de processar por vez, caso o número de elementos apresentados simultaneamente esteja além desse limiar, haverá uma sobrecarga cognitiva (Feinberg e Murphy, 2000; Sweller, 1994) impossibilitando a criação de memórias de longo prazo e a consolidação de novas informações junto aos subsunçores. Quando a quantidade de informação é maior do que capacidade de processamento imediato (Figura 1), a atenção pode concentrar-se no que não é relevante, causando o desvio da atenção do usuário durante a execução das tarefas.

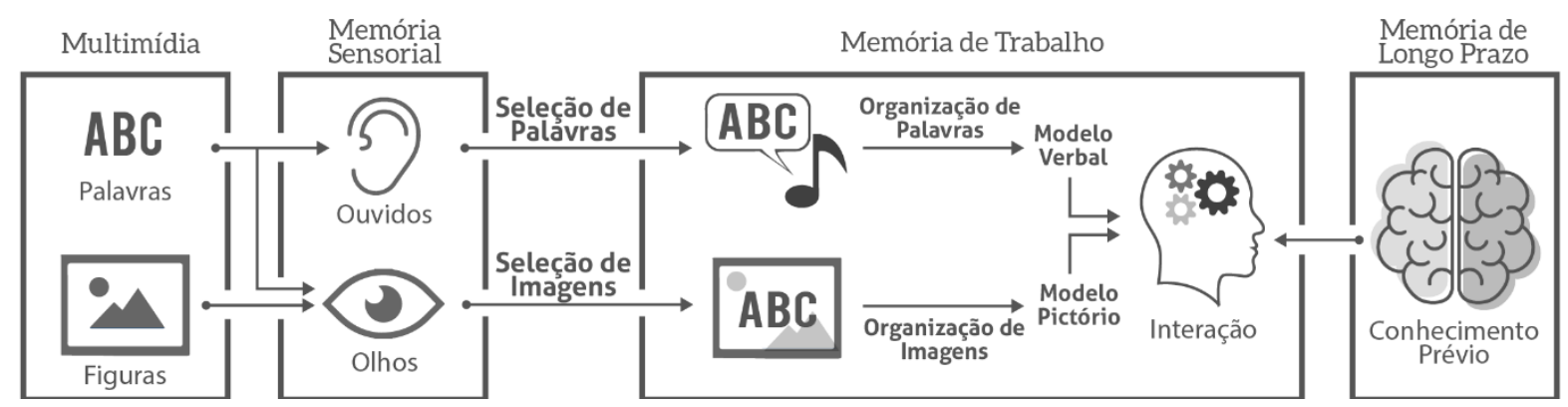

Figura 1: Esquema de processamento de informação. Fonte: Adaptado de Mayer (2009). 
De acordo com Ang, Zaphiris e Mahmood (2007) existem dois níveis de cognição, de alto e de baixo nível. $O$ alto nível pode lidar com apenas uma coisa de cada vez, enquanto o baixo nível consegue suportar diversas tarefas que são comuns. É possível que uma tarefa passe do alto para o baixo nível por repetição, quando isso acontece essa tarefa pode se tornar automática e ser executada de maneira mais rápida.

Em um jogo o aumento da carga cognitiva faz com que uma tarefa se torne mais difícil, diminuindo a carga perceptiva (estímulos capazes de prender a atenção), resultando em uma distração por parte do jogador. Se a arquitetura do jogo estiver de acordo com as estruturas biológicas humanas, com o uso frequente, os jogadores acabam se tornando praticamente imunes a distrações e conseguem se concentrar na tarefa que precisam resolver, pois, ao longo do tempo conseguirão melhorar a capacidade visual de processamento de informações (Lavie, 2005). Existem técnicas capazes de diminuir a carga cognitiva em alguns contextos e que podem ser aplicadas a jogos, incluindo, eliminação de ação redundante; combinação de estímulos visuais e auditivos; e apresentação de apenas uma representação por vez ao usuário (Feinberg e Murphy, 2000).

Ao avaliar a forma como as pessoas aprendem, Mayer (2009) incorporou as pesquisas anteriormente citadas no desenvolvimento de um modelo para criação de objetos digitais com vistas a aprendizagem, defendendo que esta ocorre de forma mais eficiente quando a apresentação do conteúdo é realizada concomitantemente por meio de palavras e imagens. A Teoria Cognitiva da Aprendizagem Multimídia - TCAM (Mayer, 2009) explica que estímulos nas memórias sensorial e de trabalho são fundamentais para os processos que possibilitam ao usuário desenvolver memórias de longo prazo. Isso acontece através de associações realizadas entre palavras e imagens processadas pelo sistema cognitivo humano.

Considerando as bases biológicas da aprendizagem e leitura, defendidas pela neurociência, faz-se necessário o uso de interfaces gráficas capazes de prover compreensão cabível ao córtex occípito-temporal esquerdo, pois é no córtex que ocorre a aprendizagem, por ser a região com o maior número de neurônios especializados. São eles que possuem o maior contato com as entradas visuais (Dehaene, 2012).

A Teoria Cognitiva da Aprendizagem Multimídia destaca que ao desenvolver materiais multimídia devem ser levados em consideração doze princípios, uma vez que os usuários sofrem três tipos de processamento cognitivo durante a aprendizagem: i) Redução do Processamento Estranho, ii) Gerenciamento do Processamento Essencial e iii) Processamento Generativo (Sweller, 2011).

$\mathrm{Na}$ redução do processamento Estranho, Mayer (2009) explica que informações desnecessárias devem ser excluídas do processo de aprendizagem. No processamento Cognitivo Essencial as informações prévias e necessárias devem ser repassadas de maneira adequada para cada aluno e no processamento Generativo isso deve ser considerado por ser inerente às estruturas adquiridas. A Figura 2 ilustra os três tipos de processamentos cognitivos usados durante a aprendizagem e seus doze princípios associados. 


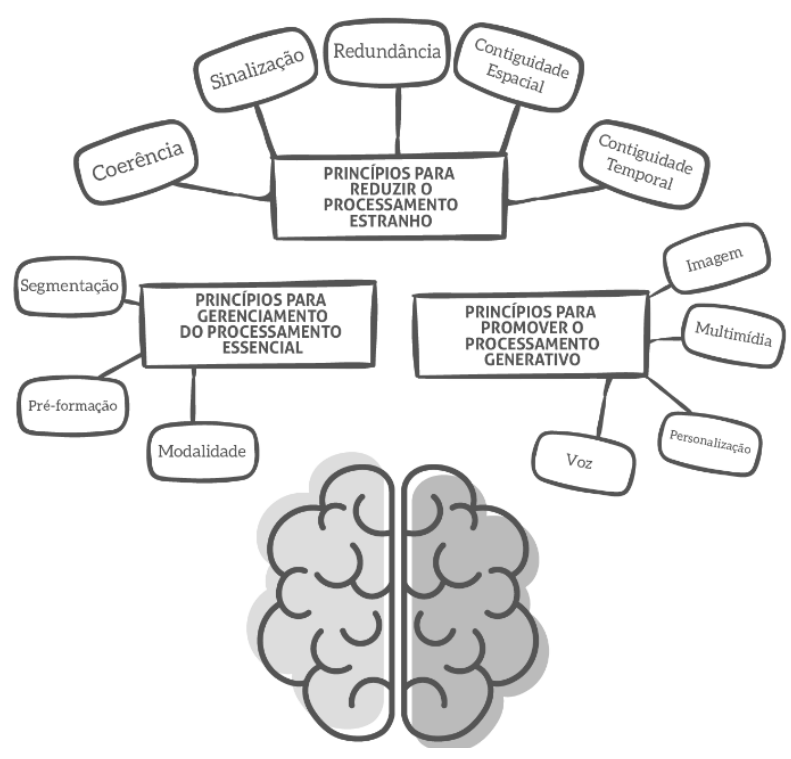

Figura 2: Tipos de processamento usados na Teoria Cognitiva da Aprendizagem Multimídia.

A criação de jogos com objetivo de auxiliar na aprendizagem pressupõe conhecimentos sobre como o cérebro processa as informações, para que estas sejam incorporados à arquitetura do jogo. Durante o processo de criação do Livro do Conhecimento, foram considerados tantos os pressupostos biológicos defendidos pela Teoria da Carga Cognitiva e Teoria Cognitiva da Aprendizagem Multimídia, quanto a mecânica e gameplay ligadas à aprendizagem significativa que poderiam ser incorporados ao escopo do jogo, tendo como objetivo alcançar melhores resultados.

\section{Trabalhos relacionados}

As mudanças no cenário científico e tecnológico modificaram também o panorama educacional, sobretudo na utilização de ferramentas dentro e fora de sala de aula, que geram estímulos diferenciados, alterando, inclusive, a forma como os seres humanos processam a informação (Carr, 2011). Em uma sociedade conectada, criar laços entre os estudantes e o que estes precisam aprender pede um olhar diferenciado. Muitos se voltam para a busca de alternativas que atendam a essa nova sociedade de forma eficiente, isto significa a "digitalização" não só de ferramentas, mas de processos, objetos, técnicas, entre outros. Considerando os problemas citados no que diz respeito às taxas de analfabetismo e ao letramento, algumas possibilidades têm sido levantadas de forma a potencializar o uso das tecnologias digitais aplicadas à educação.

Diante desse cenário, os jogos têm se revelado como mecanismos capazes de promover aprendizagem de forma lúdica. Em um jogo o acerto é bem pontuado, o usuário se sente desafiado a cumprir o que lhe foi proposto e os erro podem gerar motivação. Para Gee (2003), todos deveríamos aprender como modelar processos de aprendizagem através das mecânicas e universos propostos pelos jogos. Adentrando ainda mais no tema de aprendizagem através de jogos, tem-se a rubrica de serious games educacionais, ou ainda jogos educacionais defendidos por Slimani (2016) como ferramentas de aprendizagem capazes de tornar o processo de construção do conhecimento agradável, mais fácil de memorizar e capaz de promover engajamento, como relatado no framework desenvolvido por Price et al (2017) e também em diversos serious games que tratam desde aprendizagem sobre o espaço geográfico até mensurar habilidades cognitivas (Doove et al., 2018; Matias et al., 2018; Pires, Silva , et al., 2018). 
Assis et al. (2017) tendo como base o processo de aprendizagem, em que se associam palavras e imagens, propuseram a utilização de um aplicativo para dispositivos móveis, desenvolvido em Unity, intitulado “Grapphia”. O jogo é voltado para o conteúdo de ortografia de Língua Portuguesa, cujo banco de dados possui o mesmo grupo semântico de palavras. O foco do aplicativo é a escrita de palavras com dígrafos ou letras que possuem o mesmo som e seu públicoalvo são crianças de 8 a 10 anos. Diferente do jogo aqui proposto, “Grapphia” é apresentado como um aplicativo digital para dispositivos móveis, sua interface, mostra-se como um ambiente gamificado, não propriamente um jogo.

Uma das expressões do crescente incentivo à utilização de dispositivos móveis no cenário educacional é o serious game “AmarganA”, proposto por Yamato, Corrêa e Martins (Yamato et al., 2017). O jogo foi desenvolvido para as plataformas iOS e Android, usando LUA como linguagem de programação. É do tipo casual e tem por objetivo auxiliar no processo de aprendizagem de ortografia. Os autores realizaram testes de usabilidade com estudantes do Ensino Fundamental I (público-alvo do jogo), que indicam uma boa aceitação por parte do público. Por ser um jogo casual, o "AmarganA" não apresentou uma narrativa e nem sistema de recompensa associado à jornada do herói, como no Livro do Conhecimento, porém, os dois jogos têm como proposta auxiliar a aprendizagem de ortografia da Língua Portuguesa.

Barboza et al (2015) apresentam o jogo educacional intitulado "Brincando com as Letras", cujo objetivo é promover a aprendizagem do alfabeto para crianças. O jogo proporciona um ambiente em que é possível associar o som às letras correspondentes, o mesmo acontece com palavras que podem ser compostas durante a gameplay. Desenvolvido na game engine Unity e voltado para plataformas móveis e desktop, o jogo tem como público-alvo crianças a partir de 5 anos. Diferente da proposta aqui apresentada, esse jogo é para a fase de alfabetização, embora o intuito de alinhar entretenimento com aprendizagem, focando na motivação e engajamento dos estudantes no que tange à Língua Portuguesa, sejam os mesmos.

Para auxiliar na aprendizagem de Língua Portuguesa de forma prática através de dispositivos móveis, Zemor et al. (2015) propõem a ferramenta "Carnaval”, um objeto digital de aprendizagem, para plataformas móveis (celulares e tablets), na forma de um mascote virtual, que tem como objetivo fazer com que o jogador cuide de um mascote virtual, podendo desenvolvê-lo através de testes diários que são realizados através da interação com o mascote. A ferramenta foi desenvolvida por meio das tecnologias HTML5, CSS3 e JavaScript, com conteúdo pedagógico divido em níveis e sem especificação de público-alvo. Os autores mantiveram o foco no desenvolvimento do jogo, com o intuito de produzir uma ferramenta prática e de fácil acesso.

Focando na evolução dos métodos de aprendizagem e na inovação das novas tecnologias em sala de aula, Faria e Colpani (2017) propuseram o desenvolvimento do serious game "Joy e as Letrinhas” para desktop. O serious game foi desenvolvido na plataforma Construct2 e tem como objetivo auxiliar crianças de 6 a 8 anos em seu processo de alfabetização. Foram aplicados testes avaliativos de caráter quali-quanti, para validar o uso da ferramenta. Ao realizar comparações entre pré e pós-teste, o jogo mostrou auxiliar na evolução das habilidades das crianças, evidenciado através dos resultados dos testes. A ferramenta foi avaliada como lúdica, divertida e capaz de despertar o interesse dos estudantes, promovendo interação e possibilitando a realização das atividades. Os objetivos desse jogo serviram como inspiração para o desenvolvimento do Livro do Conhecimento, com o diferencial de utilizar um formato de aventura medieval.

Oliveira, Castro, Ferreira e Ouverney-King (2017) desenvolveram o aplicativo móvel "Super-hífen" com a finalidade de auxiliar na aprendizagem da nova ortografia da Língua Portuguesa, com foco na utilização do hífen. O jogo foi construído na ferramenta Construct2, tem como público-alvo estudantes do Ensino Médio e visa promover reflexões sobre o conteúdo de forma lúdica e motivacional. A partir de testes realizados os autores obtiveram resultados positivos 
quanto à usabilidade e interatividade. A ferramenta é um recurso alternativo de aprendizagem e aproveita os elementos presentes em jogos digitais para o processo de construção do conhecimento, tornando-o divertido assim como a proposta do Livro do Conhecimento.

\section{Desenvolvimento do jogo}

Esta seção descreve as etapas, cenário e ferramentas de desenvolvimento do jogo. A ferramenta foi proposta como resultado de uma disciplina do curso de Licenciatura em Computação. Participaram da concepção e desenvolvimento do jogo dois estudantes universitários e uma professora da área de Computação. O levantamento dos requisitos do jogo foi realizado com uma professora com formação em Língua Portuguesa e atuação no Ensino Fundamental e Médio de uma escola particular do município de [omitido para revisão], que além de descrever como os assuntos são abordados em sala de aula, destacou as principais dificuldades enfrentadas pelos estudantes. Os membros participaram de todas as etapas do desenvolvimento porém as responsabilidades foram divididas de tal forma que, a professora da área de Computação foi responsável pelo acompanhamento de todas as etapas do processo de desenvolvimento do jogo como Learning Designer e Gamer Designer na definição de público-alvo, processo de aprendizagem, planejamento dos testes, avaliação de elementos de jogo. Os acadêmicos de Licenciatura em Computação foram os responsáveis pelo desenvolvimento do jogo. e aplicação dos testes.

\subsection{Etapas do Desenvolvimento}

Levando em conta os dados levantados sobre o desempenho dos estudantes brasileiros na disciplina de Língua Portuguesa, optou-se por trabalhar com o tema ortografia. Desta forma, o problema a ser tratado no jogo refere-se à grafia correta de algumas palavras. O jogo foi projetado para usuários com idade a partir de 10 anos, uma vez que o problema relacionado à grafia incorreta de palavras vem desde os anos iniciais da escola e nesta idade o estudante começa a aprender conteúdos mais complexos, quando comparado com os primeiros anos do Ensino Fundamental. O jogo o Livro do Conhecimento, foi desenvolvido para desktop, considerando que nas escolas há laboratórios de informática e este pode ser utilizado como apoio às aulas.

Para o desenvolvimento do jogo O Livro do Conhecimento foram seguidas cinco etapas, que são: Brainstorm, Especificação dos Requisitos do Jogo, Planejamento, Prototipação e Testes, conforme ilustradas na Figura 3 e descritas a seguir. 


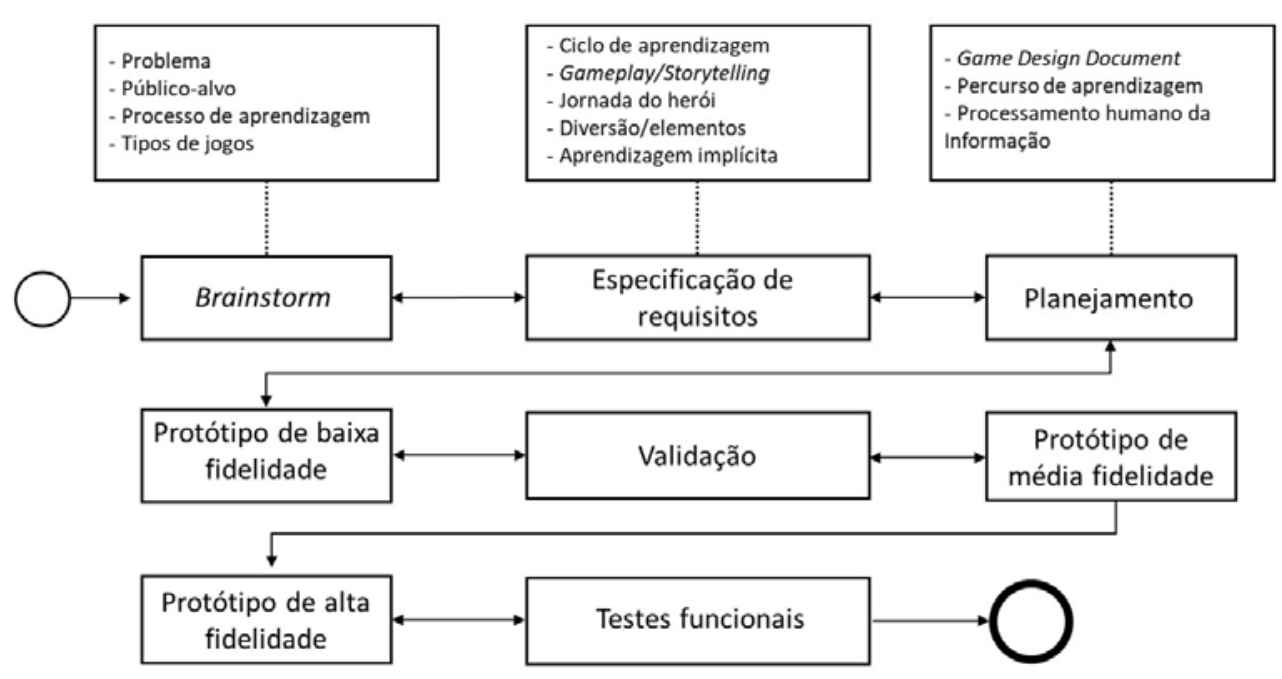

Figura 3: Etapas do desenvolvimento do jogo e suas conexões.

A primeira etapa foi o Brainstorm com a equipe desenvolvedora, que analisou o problema levantado, neste caso ortografia da Língua Portuguesa. Foram levantadas as dificuldades de aprendizagem enfrentadas pelo público-alvo e os tipos de jogos que mais atraem a atenção das pessoas, suas causas, como esses jogos poderiam ser consorciados ao que se conhece sobre a arquitetura da aprendizagem humana e como isso pode ter impacto direto na aprendizagem.

A segunda etapa foi a Especificação dos Requisitos do Jogo, onde percebeu-se que as aventuras vistas em jogos de plataforma possibilitam a promoção da aprendizagem implícita pelo roteiro, jornada do herói e fatores imersivos em um mundo virtual. É possível embutir na gameplay os requisitos de aprendizagem seguindo teorias de aprendizagem cognitivas e o que se conhece de mecanismos biológicos de criação de memórias de longo prazo, ressaltando a hipótese de que as narrativas têm um importante papel na imersão proporcionada ao jogador (Lugmayr et al., 2017). Para cumprir esses requisitos, nessa etapa foram consideradas: i) uma narrativa coerente com o universo do jogo a ser desenvolvido, ii) a jornada do herói, iii) a possibilidade de autorregulação de aprendizagem a ser definida pelos níveis de jogo e pelas etapas ultrapassadas e iv) quais elementos de diversão deveriam ser considerados para prender a atenção do usuário. Nesse momento, a partir da narrativa, definiu-se o universo do jogo e por consequência a jornada do herói, a mecânica a ser implementada e o ritmo que seria estabelecido, tendo como elemento direcionador a história. Para Padilha-Zea et al (2014), narrativa é um dos elementos que mantém a motivação dos estudantes em um jogo educacional, o que torna a experiência mais imersiva, caracterizada por despertar sentimentos parassociais, aqueles desenvolvidos no jogador diante dos personagens da trama. Esses permitem que o jogador sinta-se com o dever de proteger o personagem principal e ultrapassar os desafios (Padilla-Zea et al., 2014). Dessa forma, durante o projeto do jogo, definiu-se que na história do Livro do Conhecimento, que se passa em cenário medieval, o jogador se coloca no papel de uma guerreira para reestabelecer a paz em seu reino.

Após a escolha das narrativas que permitem desenvolver a gameplay, foi discutido o estilo de jogo. Neste caso optou-se pelo estilo de plataforma, com mecânica baseada em alguns sucessos na indústria de jogos, como por exemplo o Super Mario World e CupHead. Segundo Rogers (2014), jogos de plataforma são aqueles em que o jogador controla os personagens pulando e se movimentando através de um ambiente composto por plataformas. A mecânica inclui ações de pular, atirar e movimentar-se pelo cenário. Além disso, a ação que mais serviu de inspiração para o jogo é o bater em caixinhas suspensas para obter coletáveis. Houve ainda adaptação ao adicionar elementos de aprendizagem, onde o jogador não precisa fazer escolhas em uma tela de perguntas 
e respostas, mas é capaz de fazer escolhas batendo em caixinhas suspensas e vencer desafios propostos nas fases. Ao fazer com que o jogador tenha acesso aos elementos de aprendizagem utilizando interface similar às dos jogos de diversão, define-se os elementos para aprendizagem implícita, em que os objetos para a aprendizagem são incutidos no cenário e no processo de evolução durante a jornada herói, evidenciando o processo de autorregulação da aprendizagem.

O processo de definição das estruturas do jogo é acompanhado do design de aprendizagem objetivando promover uma experiência imersiva para gerar engajamento. Nessa etapa, a arquitetura do jogo e seus elementos de cenário se fundem com os objetivos de aprendizagem, suportados pela Teoria Cognitiva da Aprendizagem Multimídia (Mayer, 2009) e pelos pressupostos da Teoria da Carga Cognitiva (Sweller, 2011) através de uma proposta de interface imersiva, excluindo a sobrecarga de informação por unidade de tempo (chunk) e, com isso, potencializa a Aprendizagem. São eleitos os itens de imersão “divertidos” e seus vínculos com o processo de construção e conhecimento.

Cumpridos os requisitos do jogo, a terceira etapa, o Planejamento, foi executado. Nele o que foi registrado na documentação é posto em prática, para a criação do GDD (Game Design Document). Foram elaboradas as interfaces de acordo com os mapas de processos de aprendizagem, diferenciando-se de um jogo comercial cujo foco principal está na gameplay. Nessa etapa, a mecânica foi atrelada ao roteiro de aprendizagem pretendido para possibilitar a autorregulação da aprendizagem pelo usuário, ou seja, os elementos como cenário, personagens e elementos de evolução foram ordenados de forma sincronizada para que a jornada do herói também fizesse parte do percurso de aprendizagem, proporcionando ao usuário a oportunidade de explorar o cenário e, com isso, absorver informações que são relevantes tanto para sua aprendizagem quanto para avançar no universo do jogo. O design de aprendizagem e a mecânica do jogo proveem um sistema de regras que permitem ao jogador avançar conforme sua evolução de aprendizagem, ou seja, desvendando o universo do jogo.

Com as etapas anteriores cumpridas, foram desenvolvidas as etapas de protótipos, divididas em: Protótipo de baixa fidelidade, de média fidelidade e de alta fidelidade. A etapa de Protótipo de baixa fidelidade (paper prototype) tem como objetivo obter feedback sobre o produto. Os desenvolvedores se concentram em como vai acontecer a aprendizagem e na proposta da gameplay. O desenvolvimento só avança quando o membro da equipe, especialista em design instrucional, valida o protótipo. Na sequência, a proposta é discutida com os desenvolvedores para então começar a surgir o primeiro protótipo, considerando os objetivos de aprendizagem e de promoção de engajamento a partir do flow pretendido. Enquanto houver dúvidas na construção da narrativa, jornada do herói, sistema de pontuação e outros itens que envolvem a jogabilidade e aprendizagem, são realizadas correções.

Já no Protótipo de média fidelidade, a proposta é desenhada com a ajuda de uma ferramenta de ilustração digital e impressa. Uma vez que as correções oriundas da fase anterior foram executadas, é proposto um modelo funcional de interface com o objetivo de avaliar e validar o fluxo de aprendizagem, a jogabilidade e a usabilidade do jogo. Surgem algumas ideias/dificuldades que são sanadas antes de passar para a próxima etapa. A cada modificação uma nova avaliação é realizada. Participam da avaliação os desenvolvedores, o designer instrucional e alguns estudantes de Licenciatura em Computação. 
Os protótipos de baixa e média fidelidade (Figura 4) apontaram para a necessidade de ajustes na mecânica que foram realizados antes de seguir para a próxima etapa.

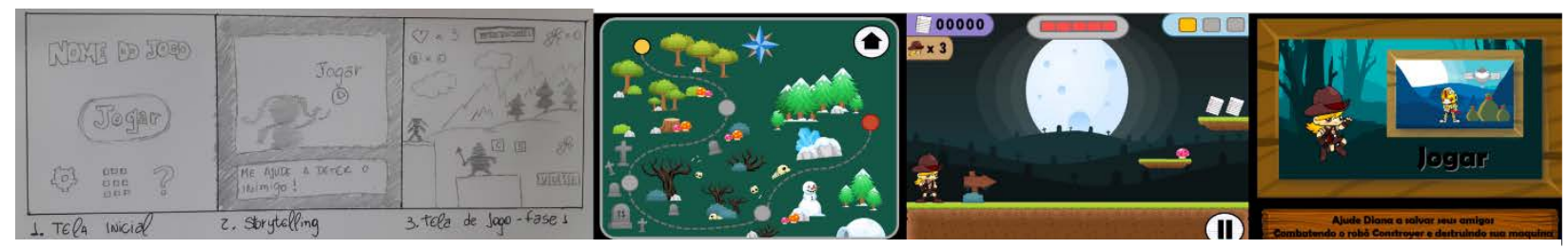

Figura 4: Protótipos de baixa fidelidade de três telas, seguidas dos protótipos de média fidelidade de outras três telas do jogo.

No Protótipo de alta fidelidade, ou protótipo digital, ocorre a implementação do jogo, uma vez que os elementos do jogo foram amadurecidos nas etapas anteriores. Foi selecionada a plataforma de desenvolvimento, as ferramentas de design, a linguagem de programação a ser usada e as ferramentas de gerenciamento de projeto que podem ser utilizadas para tornar o trabalho mais ágil. E assim, inicia-se o processo de desenvolvimento do produto. Para desenvolver o jogo $\mathrm{O}$ Livro do Conhecimento usou-se o Construct 2, pela versatilidade para criação de protótipos funcionais de jogos. $\mathrm{O}$ artefato de saída desta etapa é o jogo pronto para ser testado. À medida em que as fases do jogo vão sendo concluídas, são realizados testes funcionais para verificar se a fase está sendo executada conforme o que foi projetado.

Após a criação da primeira versão, foram realizados os testes de validação do software, com estudantes de Licenciatura em Computação e professores especialistas, apontando para a necessidade de alguns ajustes e, com isso, voltando para correções até que o jogo esteja pronto para ser testado pelos usuários finais.

\subsection{Cenário e Narrativa}

A história se passa na era medieval, em um reino chamado Damaris que tem a posse do Livro do Conhecimento. O poder do artefato permite aos súditos falar e escrever em Língua Portuguesa corretamente. No entanto, seres malignos desejam a posse do livro. Valtor, o principal vilão, reúne uma tropa de Elfos, Trolls e Orcs que avançam sobre Damaris para tomar o Livro.

Durante a batalha o rei é capturado e a rainha juntamente com as suas filhas Miriam e Diana fogem para a floresta. No entanto, são capturadas logo em seguida e apenas a princesa Diana consegue fugir, sendo encontrada por um sábio por quem é treinada. Valtor é bem-sucedido em sua investida, domina o reino, furta "O Livro do Conhecimento" que passa a ser utilizado para o mal e todos começam a se expressar de maneira incorreta. A princesa passou anos treinando arduamente com o objetivo de combater seus inimigos, enfrentar diversos desafios, recuperar o livro e retomar o controle do reino onde cresceu.

Neste jogo, o jogador vive o papel da princesa Diana, em sua jornada para trazer a paz ao reino, recuperando o livro e permitindo que as pessoas falem corretamente. Ao percorrer a plataforma, a heroína captura fragmentos do livro que a ajudarão no combate final com o vilão e os conhecimentos presentes em suas páginas são bônus que aumentam as possibilidades de vitória.

A representação visual dos elementos e a gameplay do jogo foram construídos tendo como base a narrativa desenvolvida na era medieval. O Quadro 1 apresenta a organização dos personagens, elementos que configuram a mecânica, cenário e coletáveis bem como suas funções no cenário do jogo. 
Quadro 1: Elementos presentes no jogo e suas funções.

\begin{tabular}{|c|c|}
\hline Assets & Características \\
\hline $\begin{array}{l}\text { Princesa Diana } \\
\text { (Personagem principal) }\end{array}$ & $\begin{array}{l}\text { A personagem principal tem características humanas com estilo medieval, } \\
\text { ela possui um arco e flecha que é controlado pelo jogador. }\end{array}$ \\
\hline \multirow[t]{4}{*}{ Inim } & Valtor (Elfo). \\
\hline & Trolls (1 $1^{\mathrm{a}}$ Fase). \\
\hline & Orcs (2a Fase). \\
\hline & Trolls, Orcs e Elfos ( $3^{\text {a }}$ Fase). \\
\hline \multirow[t]{2}{*}{ Cenários } & Primeira fase: Floresta aos arredores do reino. \\
\hline & Segunda e Terceira fase: Muro de entrada do reino de Damaris. \\
\hline \multirow[t]{3}{*}{ Objetos de cenário } & $\begin{array}{l}\text { Fase 1: Arvores, lagos, abismos, pedras, blocos e plataformas } \\
\text { montáveis. }\end{array}$ \\
\hline & Fase 2: abismos, blocos e plataformas montáveis. \\
\hline & Fase 3: plataforma que se movimenta em posição vertical. \\
\hline \multirow[t]{4}{*}{ H.U.D. (Head Up Displ } & $\begin{array}{l}\text { Barra de vida: mostra o nível de vida, em questão de ataques de } \\
\text { inimigos. }\end{array}$ \\
\hline & Número de vidas: indica o número de vidas que o player ainda possui. \\
\hline & $\begin{array}{l}\text { Papiros recolhidos: apresenta a quantidade de papiros que o player } \\
\text { adquiriu pela fase. }\end{array}$ \\
\hline & Barra de moedas: indica o número de joias que o player coletou. \\
\hline \multirow[t]{3}{*}{ Itens coletaveis } & Joias e saco de joias (coins). \\
\hline & Papiro: página do livro do conhecimento. \\
\hline & Maças: recuperação de energia. \\
\hline
\end{tabular}

Os princípios da Teoria da Carga Cognitiva e Aprendizagem Multimídia estão presentes em todas as fases do jogo, pois quando se faz necessário completar um obstáculo ou liberar uma parte do trajeto, ocorre aprendizagem por meio do uso de palavras, sons e imagens, além do envolvimento emocional que o jogador é levado a ter, através do enlace de pensamentos e lembranças, frutos da experiência vivida ao longo do jogo.

Durante o percurso há desafios nas fases que estimulam o jogador a superá-los usando seu conhecimento sobre ortografia. Por exemplo, ao se deparar com uma plataforma que está desabilitada ou bloqueando alguma passagem, o obstáculo conterá uma palavra com uma interrogação e para alcançar seu objetivo, o jogador deve escolher a letra correta. Em outros obstáculos o jogador encontrará palavras que estão escritas de maneira correta e outras de forma incorreta, para avançar o usuário deve usar apenas as que estão escritas corretamente. A cada obstáculo superado o jogador se aproxima das páginas perdidas do livro e ao encontrar uma página obtém diferentes informações, que mostram a distinção entre palavras que possuem escrita parecida, como por exemplo: “a gente” e "agente"; "mas" e “mais"; "esse” e “este” etc.

O jogador possui um "arco e flecha” que pode ser usado contra seus inimigos. Para derrotar o monstro é preciso atirar flechas. Há também joias que podem ser coletadas. A cada 100 joias 
adquiridas o jogador ganha uma vida. As maçãs coletadas recuperam a energia da guerreira. À medida em que o combate avança, surgem perguntas referentes aos conhecimentos adquiridos ao longo das fases dispostas nas páginas recuperadas do livro. Para responder a pergunta, o jogador deve pular e bater na caixa compatível com a resposta que ele escolher. Se errar, a punição que receberá é o restabelecimento da energia do chefão.

\subsection{Telas do Jogo}

Para melhor ilustrar o jogo, nesta seção são apresentas as principais tela do jogo. A Figura 5, ilustra a tela inicial com as funções de configuração, seguida pela storytelling retratado através das páginas do livro e o mapa de fases.

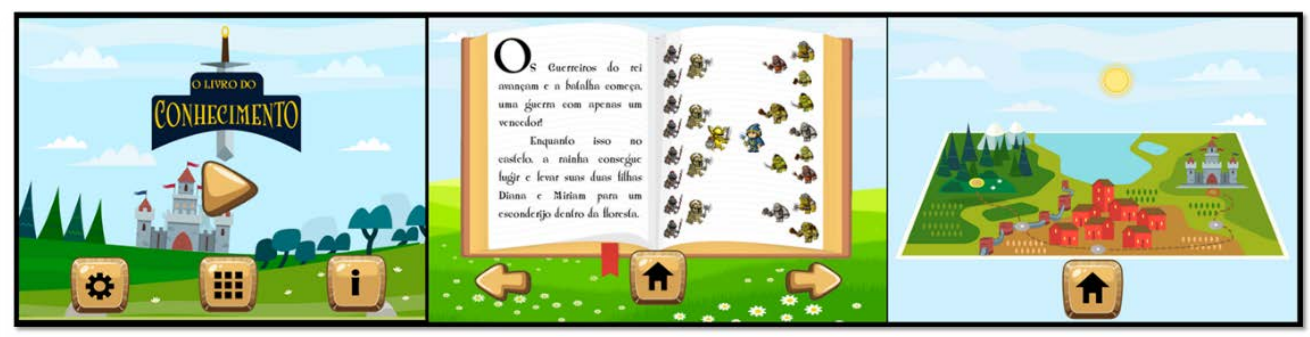

Figura 5: Tela inicial do jogo com as funções de configuração, storytelling mapa de fase.

A Figura 6 apresenta os desafios relacionados à aprendizagem da primeira fase, de acordo com a mecânica do jogo. Em um desafio, o jogador deve passar pelo rio utilizando as plataformas móveis que possuem as palavras escritas corretamente. Se o jogador utilizar uma plataforma com uma palavra errada, é apresentado o feedback de perigo na plataforma para que o jogador saia imediatamente. O objetivo da fase é recuperar as folhas do livro do conhecimento que foram perdidas. Ao encontrar uma folha, o jogador obtém uma informação acerca de uma palavra e sua aplicação correta em um contexto ortográfico.

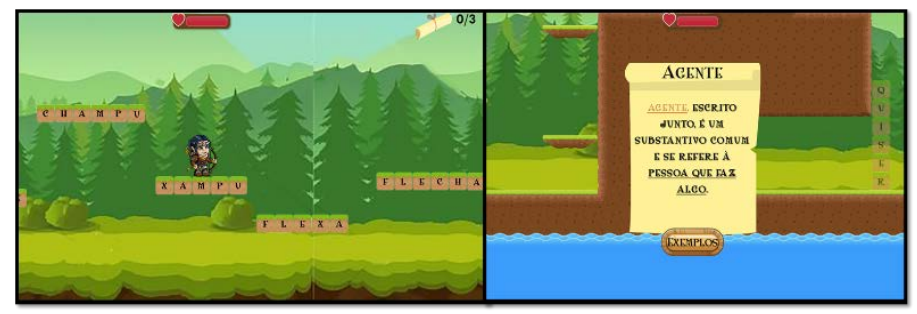

Figura 6: Desafios da primeira fase.

A Figura 7 apresenta os elementos de aprendizagem presentes na Fase 2. A imagem à esquerda da figura mostra uma plataforma com a palavra "mexer" que possui um bônus coletável. A plataforma fica alternando entre as letras $\mathrm{X}$ e $\mathrm{CH}$. Se o jogador estiver sobre a plataforma enquanto a palavra estiver escrita de forma incorreta, receberá um feedback para sair da plataforma imediatamente. Outro tipo de desafio apresentado ao jogador são as passagens bloqueadas e para desbloqueá-las o jogador deve pular e bater na letra correta para conseguir obter os coletáveis.

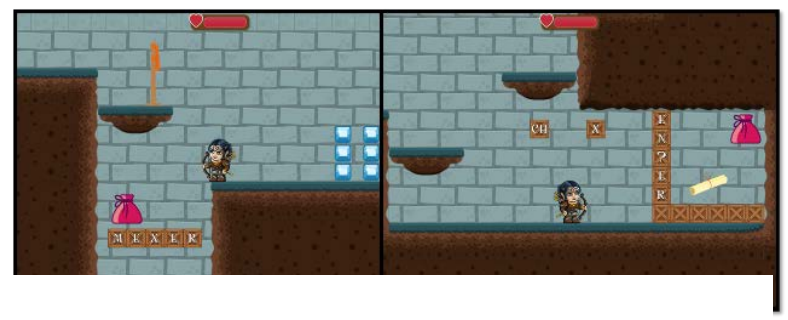

Figura 7: Elementos de aprendizagem presentes na Fase 2. 
A Figura 8 apresenta a batalha contra o primeiro chefe. A imagem à esquerda ilustra as informações repassadas ao jogador para que ele possa relembrar as informações obtidas ao coletar as páginas encontradas nas fases anteriores. Durante a fase contra o chefe, será lançado um desafio com uma pergunta relacionada ao conteúdo das páginas do livro. O jogador deve responder a cada pergunta, pulando e batendo na alternativa correta para o contexto da frase e prosseguir na luta contra o arqueiro.

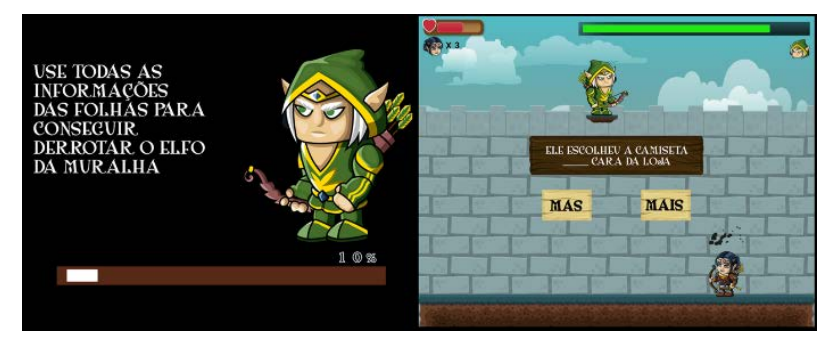

Figura 8: Batalha contra o primeiro chefe.

Com o objetivo de dar uma visão geral da ferramenta e da interação entre os estados do jogo, a Figura 9 apresenta o Diagrama de Estados. Nele é possível observar que a partir do menu inicial o usuário tem a opção de alterar as configurações, solicitar ajuda ou iniciar o jogo. Ao iniciar o jogo o usuário pode ser encaminhado para a narrativa, caso seja a primeira vez, ou para o mapa de fases.

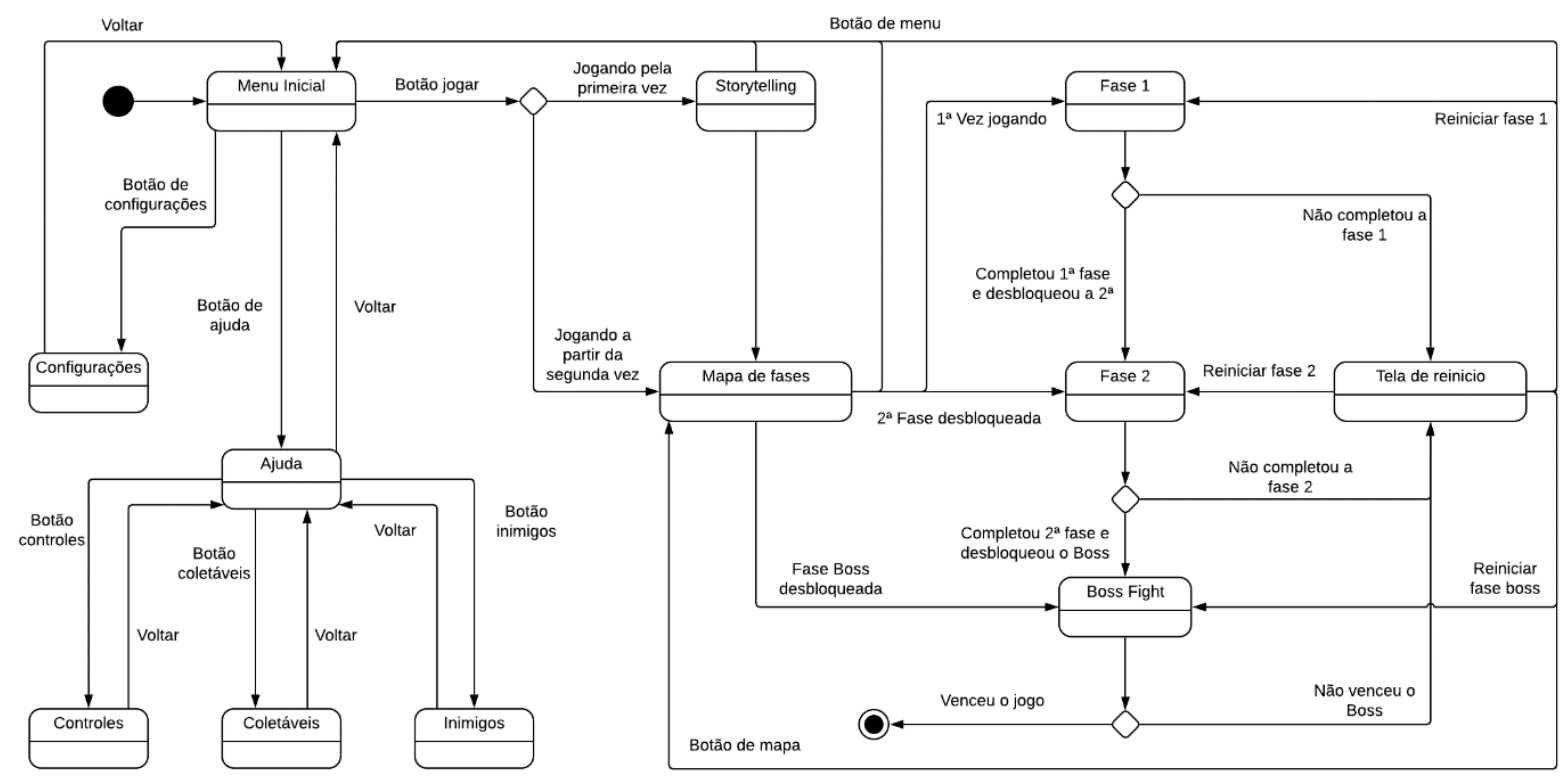

Figura 9: Diagrama de Estados do Jogo O Livro do Conhecimento.

\subsection{Ambiente de Desenvolvimento}

No que diz respeito a organização visual e de codificação, a primeira etapa consistiu na montagem dos personagens e cenários. Usou-se a técnica de composição através de imagens e sprites de livre acesso na internet. A game engine selecionada foi a Construct $2^{1}$, considerando desempenho, qualidade e facilidade do processo de produção com um sistema de programação visual através de eventos e ações definidas pelos desenvolvedores, que atende ao desenvolvimento de jogos 2D, possibilitando exportar para diversas plataformas como smartphones Android e iOS, sistemas

\footnotetext{
${ }^{1}$ Disponível em: https://www.scirra.com/construct2
} 
Windows, Mac, Linux e interfaces web. Contudo, esta primeira versão do aplicativo é para desktops, com uma versão móvel em processo de desenvolvimento.

Foram ainda utilizadas outras ferramentas durante o processo de desenvolvimento, conforme descritas no Quadro 2.

Quadro 2: Ferramentas utilizadas para a construção do jogo.

\begin{tabular}{|l|l|l|}
\hline \multicolumn{1}{|c|}{ Ferramenta } & \multicolumn{1}{c|}{ Atividade } & \multicolumn{1}{c|}{ Função } \\
\hline Trello & Organização do game & Gerência da construção do projeto \\
\hline PowerPoint 2016 & Mockup & Demo do gameplay, mecânica \\
\hline Adobe Photoshop CC 2017 & Edição de imagens & $\begin{array}{l}\text { Edição gráfica de personagens, cenários, } \\
\text { botões e assets }\end{array}$ \\
\hline Adobe Illustrator CC 2017 & Edição de imagens & Desenvolvimento do jogo \\
\hline Construct & Construção de jogos & Denongen \\
\hline
\end{tabular}

O jogo foi implementado seguindo as etapas definidas na Figura 3 e foram realizadas avaliações que estão descritas na seção seguinte.

\section{Resultados e Avaliações}

Nesta seção são apresentados os procedimentos realizados com o objetivo de avaliar o serious game educacional O Livro do Conhecimento. Nessa etapa foram avaliados os requisitos didáticos pedagógicos do jogo, a adequação da interface e a organização da informação de acordo com pressupostos cognitivos, seguindo a Teria Cognitiva da Aprendizagem Multimídia e a Teoria da Carga Cognitiva, a usabilidade, a experiência do usuário e a aceitação do jogo enquanto ferramenta de aprendizagem em Língua Portuguesa.

\subsection{Avaliação comparativa com outras ferramentas}

Durante o processo de revisão da literatura foi realizada uma busca por trabalhos que relatassem jogos/objetos digitais de aprendizagem cujo objetivo fosse semelhante ao do Livro do Conhecimento. Nesses trabalhos, foram verificados, sobretudo, os critérios de avaliação pautados em três pilares: jogos, aspectos didáticos pedagógicos dos jogos e a experiência do usuário, defendidos na literatura.

Na Tabela 1 é possível verificar a relação entre os critérios de avaliação do jogo "O livro do Conhecimento” e os demais jogos pesquisados. Os jogos são comparados seguindo aspectos didáticos-pedagógicos e critérios do E-Game Flow, considerando 1 se atende ao critério e 0 caso contrário. Como os jogos não estão disponíveis para serem jogados, as informações sobre cada critério foram recuperadas dos artigos que formalizam os jogos. É possível observar que o serious game educacional proposto, cumpriu os requisitos definidos como essenciais, tanto pelo E-Game Flow quanto pelos aspectos didáticos e pedagógicos (Araújo e Freitas, 2017) porém, é importante esclarecer que o critério Reusabilidade, no contexto desta avaliação, levou em consideração que é possível que o jogo seja utilizado em diferentes salas, porém não é possível a reutilização das fases de forma independente para serem aplicadas a diferentes contextos ou aplicativos. 
Tabela 1: Avaliação comparativa entre o jogo proposto e jogos similares.

\begin{tabular}{|c|c|c|c|c|c|c|c|c|c|}
\hline \multirow[b]{2}{*}{ Categoria } & \multirow[b]{2}{*}{ Critério } & \multicolumn{8}{|c|}{ Jogos educacionais } \\
\hline & & $\begin{array}{c}\text { O Livro do } \\
\text { conhecimento } \\
\text { (Pires, Michel, et } \\
\text { al., 2018) }\end{array}$ & $\begin{array}{l}\text { Grapphia } \\
\text { (Assis et } \\
\text { al., 2017) }\end{array}$ & $\begin{array}{c}\text { AmarganA } \\
\text { (Yamato et al., } \\
\text { 2017). }\end{array}$ & \begin{tabular}{|c|} 
Brincando \\
com as \\
letras \\
(Barboza Jre \\
Silveira, 2015)
\end{tabular} & $\begin{array}{c}\text { Letra } \\
\text { Livre 2.0 } \\
\text { (A. M. } \\
\text { Oliveira et } \\
\text { al., 2017) }\end{array}$ & $\begin{array}{l}\text { Carnaval } \\
\text { (Zemor et } \\
\text { al., 2015) }\end{array}$ & \begin{tabular}{|c|} 
Joy e as \\
Letrinhas \\
(Faria e \\
Colpani, \\
2017)
\end{tabular} & $\begin{array}{l}\text { Super- } \\
\text { hífen } \\
\text { (A. C. C. d. } \\
\text { Oliveira et } \\
\text { al., 2017) }\end{array}$ \\
\hline \multirow{5}{*}{ 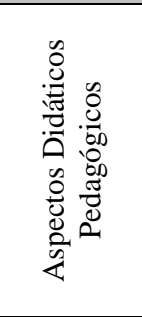 } & \begin{tabular}{|l} 
Concepção de \\
Linguagem
\end{tabular} & 1 & 1 & 1 & 1 & 1 & 1 & 1 & 1 \\
\hline & $\begin{array}{l}\text { Granularidade } \\
\text { /Reusabilidade }\end{array}$ & 1 & 0 & 0 & 0 & 0 & 1 & 0 & 1 \\
\hline & \begin{tabular}{|l|}
$\begin{array}{l}\text { Estruturação de } \\
\text { conteúdo }\end{array}$ \\
\end{tabular} & 1 & 1 & 1 & 0 & 1 & 1 & 1 & 1 \\
\hline & Sistema de Ajuda & 1 & 0 & 1 & 0 & 0 & 0 & 1 & 0 \\
\hline & \begin{tabular}{|l|}
$\begin{array}{l}\text { Objetivo de } \\
\text { aprendizagem }\end{array}$ \\
\end{tabular} & 1 & 1 & 1 & 1 & 1 & 1 & 1 & 1 \\
\hline \multirow{8}{*}{ 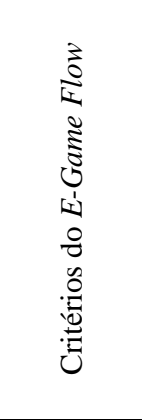 } & Concentração & 1 & 0 & 0 & 1 & 1 & 1 & 1 & 1 \\
\hline & Desafio & 1 & 1 & 0 & 1 & 0 & 0 & 1 & 1 \\
\hline & \begin{tabular}{|l|}
$\begin{array}{l}\text { Habilidades do } \\
\text { jogador }\end{array}$ \\
\end{tabular} & 1 & 1 & 1 & 1 & 1 & 0 & 1 & 1 \\
\hline & Controle & 1 & 0 & 1 & 1 & 1 & 1 & 1 & 1 \\
\hline & Objetivos & 1 & 1 & 1 & 1 & 1 & 1 & 1 & 1 \\
\hline & Feedback & 1 & 1 & 1 & 0 & 1 & 1 & 1 & 0 \\
\hline & Imersão & 1 & 1 & 0 & 0 & 1 & 1 & 0 & 1 \\
\hline & Interação & 0 & 0 & 0 & 0 & 0 & 1 & 1 & 0 \\
\hline \multicolumn{2}{|c|}{ Total } & $100 \%$ & $62 \%$ & $62 \%$ & $54 \%$ & $69 \%$ & $77 \%$ & $85 \%$ & $77 \%$ \\
\hline
\end{tabular}

\subsection{Avaliação quanto ao modelo de Processamento da Informação}

Durante o processo de desenvolvimento e prototipação foram aplicados testes pelos desenvolvedores com a finalidade de verificar se a disposição da interface estava de acordo com a Teoria Cognitiva da Aprendizagem Multimídia, para avaliar a adesão ao modelo de processamento da informação em dispositivos multimídia. O teste foi realizado por três desenvolvedores, todos estudantes de Licenciatura em Computação da Universidade [omitido para revisão] que analisaram, em conjunto, a organização das telas, levando em consideração os doze princípios de Richard Mayer (2009).

A Tabela 2 apresenta o enquadramento do jogo O Livro do Conhecimento, em cada um dos 12 princípios. No campo status é considerado 1 se o jogo atende ao critério e 0 caso não atenda. Dentre os critérios avaliados o único que não foi atendido foi o critério "Voz" uma vez que o jogo não possui narrativa em áudio. Entretanto, o critério Contiguidade Espacial foi atendido parcialmente pois em jogos de plataforma não é possível ter acesso a todo o cenário de uma só vez já que a tela exposta corresponde à área da câmera focada no personagem em ação.

Tabela 2: Enquadramento dos princípios do processamento da informação de Richard Mayer.

\begin{tabular}{|l|l|c|}
\hline \multicolumn{2}{|c|}{ Princípios } & Status \\
\hline \multirow{4}{*}{$\begin{array}{l}\text { Princípios para reduzir o } \\
\text { processamento estranho }\end{array}$} & Coerência & 1 \\
\cline { 2 - 3 } & Sinalização & 1 \\
\cline { 2 - 3 } & Redundância & 1 \\
\cline { 2 - 3 } & Contiguidade Espacial & 0 \\
\cline { 2 - 3 } & Contiguidade Temporal & 1 \\
\hline \multirow{2}{*}{$\begin{array}{l}\text { Princípios para } \\
\text { Gerenciamento do }\end{array}$} & Segmentação & 1 \\
\cline { 2 - 3 } & Pró-formação & 1 \\
\cline { 2 - 3 } $\begin{array}{l}\text { Princípios para promover o o } \\
\text { Processamento Essencial }\end{array}$ & Modalidade & 1 \\
\cline { 2 - 3 } & Multimídia & 1 \\
\cline { 2 - 3 } & Personalização & 1 \\
\cline { 2 - 3 } & Voz & 1 \\
\cline { 2 - 3 } & Imagem & \\
\hline
\end{tabular}




\subsection{Avaliação quanto aos requisitos de jogos e de aprendizagem}

Para que os jogadores tenham uma experiência de jogo adequada, a usabilidade é essencial, se mal elaborada pode causar desvios de atenção (Gurgel et al., 2006). Com o objetivo de avaliar o nível de diversão, imersão e prazer que o jogo de aprendizagem proporciona, foi utilizado o método $E$ Game Flow (Sweetser e Wyeth, 2005), que objetiva aplicar heurísticas quanto à usabilidade e experiência do jogador. O método E-Game Flow tem como base a Teoria do Fluxo e possui a finalidade de explicar características que tornam agradável uma atividade. O psicólogo Mihaly Csikszentmihalyi (Sweetser e Wyeth, 2005), destacou o estado de Fluxo como uma experiência gratificante em que o usuário se sente imerso na realização de uma atividade por vontade própria.

Para a avaliação de jogos, o método E-Game Flow propõe oito categorias: Concentração, Desafio, Habilidades do Jogador, Controle, Objetivos, Feedback, Imersão e Interação (Sweetser e Wyeth, 2005). O Quadro 3 descreve cada um dos critérios.

Quadro 3: Critérios do E-Game Flow.

\begin{tabular}{|l|l|}
\hline \multicolumn{1}{|c|}{ Critério } & \multicolumn{1}{c|}{ Descrição } \\
\hline Concentração & Retenção do foco e atenção do usuário, sem sobrecarga com tarefas não essenciais. \\
\hline Desafio & Os desafios não devem oferecer uma pressão excessiva e nem gerar apatia. \\
\hline $\begin{array}{l}\text { Habilidades do } \\
\text { jogador }\end{array}$ & $\begin{array}{l}\text { A experiência de jogo deve fornecer tarefas que proporcionem o desenvolvimento de } \\
\text { habilidades do jogador, através de um processo divertido e motivador. }\end{array}$ \\
\hline Controle & O jogador deve possuir controle sobre os elementos e objetivos do jogo. \\
\hline Objetivos & $\begin{array}{l}\text { Os objetivos devem ser especificados, deixando claro aos usuários ementos } \\
\text { adequados. }\end{array}$ \\
\hline Feedback & $\begin{array}{l}\text { São as informações que o jogador deve receber acerca do seu progresso e resultados das ações } \\
\text { de suas tarefas. }\end{array}$ \\
\hline Imersão & $\begin{array}{l}\text { Os jogadores se sentem transportados ao universo do jogo, fazendo com que o usuário perca } \\
\text { o senso de tempo e consciência do que acontece à sua volta. }\end{array}$ \\
\hline Interação & $\begin{array}{l}\text { O jogo proporciona oportunidades de interação com outros jogadores, competição, salas de } \\
\text { chat on-line etc. }\end{array}$ \\
\hline
\end{tabular}

Com base nas categorias propostas pelo método E-Game Flow (Sweetser e Wyeth, 2005), o Gráfico 1 apresenta a pontuação alcançada pelo Livro do Conhecimento em cada critério, após a avaliação de doze jogadores que participaram da experiência de utilizá-lo. Foi aplicada a escala Likert em que 1: não se aplica, 2: deveria, mas não tem, 3: ruim, 4: bom e 5: ótimo. A avaliação foi realizada com um grupo de estudantes de escola técnica, todos pertencentes ao Ensino Médio e com faixa etária entre 17 e 20 anos, todos os estudantes informaram ter experiência em jogos. 


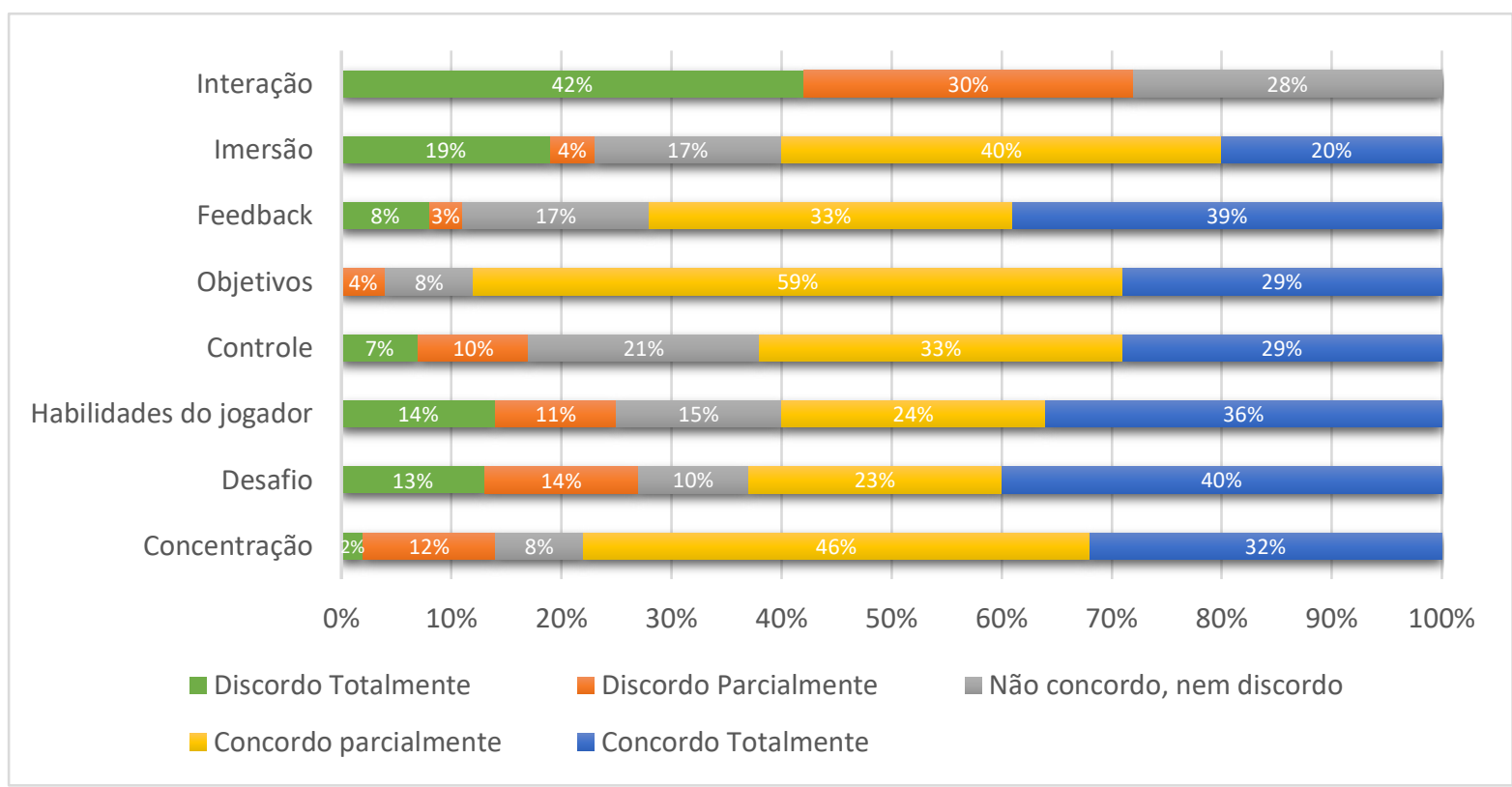

Gráfico 1: Resultados da avaliação pelos usuários com o método E-Game Flow.

As avaliações revelam que o jogo O Livro do Conhecimento atingiu desempenho entre bom e ótimo, nos seguintes critérios: 78\% concentração, 63\% desafios apresentados, 60\% em Habilidades do jogador, 62\% em Controle, $88 \%$ nos objetivos, $72 \%$ de feedback, $60 \%$ de imersão e $0 \%$ em interação. As categorias que tiveram destaque positivo foram concentração, objetivos e feedback. Dados sugerem que o jogo tem objetivos claros, atrai a atenção de quem joga por ter uma narrativa envolvente e tem feedbacks importantes para o desenvolvimento do jogo. Porém, nos critérios desafios, habilidades do jogador, controle e imersão, há indícios de que são necessários ajustes. A interação recebeu $0 \%$, dentro do intervalo destacado, pois o jogo não oferece um modo multiplayer on-line, chat ou salas de bate papo.

Os resultados obtidos foram importantes para ajustes e melhorias no processo de desenvolvimento. Entretanto, os usuários mostraram-se satisfeitos com o uso do jogo, história envolvida e simplicidade na mecânica apresentada. Foi detectada a necessidade de adição de novas fases e uma versão para dispositivos móveis.

\subsection{Avaliação MEEGA+}

Com a finalidade de avaliar o jogo com o público-alvo direto, foi utilizado o MEEGA+, um método de avaliação de jogos educacionais (Petri et al., 2016), que embora seja aplicado a jogos educacionais para Computação, pode ser usado em outras áreas.

O método se divide em duas grandes categorias: usabilidade e experiência do jogador, na primeira categoria são verificados quatro critérios e na segunda categoria sete, como descritas a seguir.

A avaliação de usabilidade é subdividida em 5 aspectos: i) aprendizibilidade é o fator que avalia a possibilidade de aprender a usar o jogo com eficácia, eficiência, liberdade de risco e satisfação (ISO/IEC, 2014); ii) operabilidade avalia se o jogo possui elementos que facilitam o controle e a operação; iii) estética trata de avaliar se a interface do jogo é agradável e satisfatória para o usuário; iv) acessibilidade avalia se o jogo pode ser usado por pessoas deficientes visuais ou daltônicas; e a v) proteção de erros do usuário avalia se o jogo protege o usuário de erros (este item de avaliação é atribuído apenas para jogos digitais). Entretanto, o aspecto acessibilidade foi 
desconsiderado na análise uma vez que não havia alunos com deficiência visual e o jogo não foi projetado para atender este público.

Para a avaliação da experiência do usuário são abordados sete itens: i) a confiança avalia se os usuários conseguem progredir no conteúdo abordado através de habilidade e esforço; ii) desafio avalia se o jogo se mantém desafiador ao nível de competência do aluno, a dificuldade deve aumentar em um ritmo adequado de acordo com a curva de aprendizagem; iii) satisfação avalia se o usuário sente que o esforço aplicado no jogo resulta em aprendizagem; iv) a interação social diz respeito à promoção de um ambiente compartilhado, onde existem atividades de cooperação e competição; v) a diversão é o fator que avalia o prazer, a felicidade e a distração dos usuários perante o jogo; vi) atenção focada avalia a concentração, atenção e dissociação temporal do usuário; e vii) a relevância avalia se o usuário percebe a consistência da proposta educacional e consegue vincular o conteúdo abordado ao seu futuro profissional ou acadêmico (Petri et al., 2016).

O método de pesquisa adotado foi exploratório com análise qualitativa. Participaram da avaliação do jogo um grupo de 20 alunos, sendo $n=15$ do $1^{\circ}$ ano do Ensino Médio e $n=05$ do $2^{\circ}$ ano do Ensino Médio, 60\% meninas e 40\% meninos, com idade entre 15 e 18 anos. Os estudantes jogaram por meia hora e em seguida responderam ao formulário MEEGA+, com 32 perguntas (uma vez que foram excluídas as duas perguntas relacionadas a acessibilidade), referentes às variáveis anteriormente descritas. O formulário usa escala Likert distribuída da seguinte forma: -2 “discordo totalmente", -1 “discordo", 0 “nem discordo, nem concordo", 1 “concordo" e 2 "concordo totalmente".

Na Tabela 3 são apresentados os resultados da avaliação MEEGA+ e no Gráfico 2 é ilustrada a distribuição quanto a escola Likert.

Tabela 3: Resultado do teste MEEGA+

\begin{tabular}{|l|c|c|}
\hline \multicolumn{1}{|c|}{ Classificação } & respostas & \% \\
\hline Discordo Totalmente & 25 & $4 \%$ \\
\hline Discordo & 14 & $2 \%$ \\
\hline $\begin{array}{l}\text { Nem discordo e nem } \\
\text { concordo }\end{array}$ & 35 & $5 \%$ \\
\hline Concordo & 135 & $21 \%$ \\
\hline Concordo totalmente & 431 & $68 \%$ \\
\hline Total & $\mathbf{6 4 0}$ & $\mathbf{1 0 0 \%}$ \\
\hline
\end{tabular}

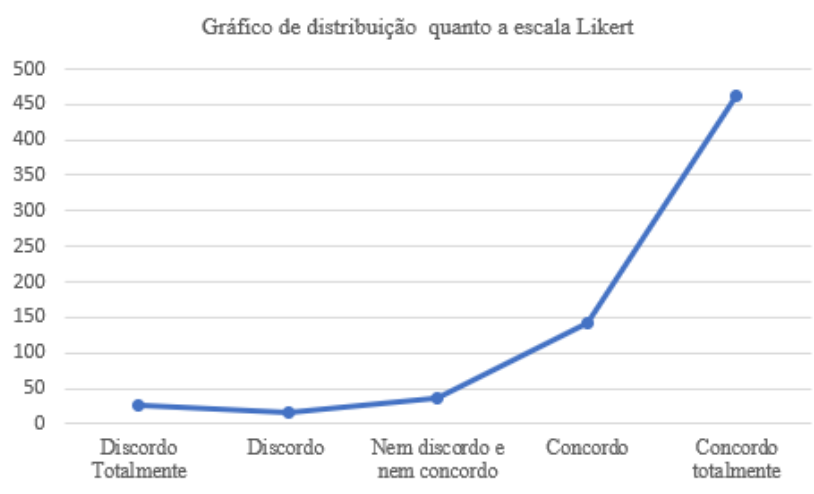

Gráfico 2: Distribuição quanto à escala Likert.

O Gráfico 3 apresenta os critérios avaliados pelo teste MEEGA+ e a distribuição das respostas dos usuários. Como é possível observar, a soma entre concordo e concordo totalmente é de $89 \%$, chamam a atenção as rubricas de Aprendizibilidade, Objetivos de Aprendizagem, Diversão, Confiança, pois as porcentagens alcançadas em concordo plenamente são superiores a $60 \%$. Ao analisar a relação entre as rubricas Objetivos de Aprendizagem e Diversão verifica-se um bom grau de aceitação, o que é um ponto positivo uma vez que uma das propostas do trabalho, em resposta a um item levantado pela sociedade científica é “como criar sérious game divertidos?”. Apesar do jogo não ter a possibilidade de ser utilizado on-line, durante a aplicação os colegas ajudaram uns aos outros, seja com dicas de resolução seja com dicas de como superar os obstáculos mecânicos interpostos. Durante a aplicação ouvia-se "vai por lá", "volta e pega o pergaminho", 
por esse motivo, optou-se por não excluir a variável do teste, pois a colaboratividade deu-se de forma presencial.

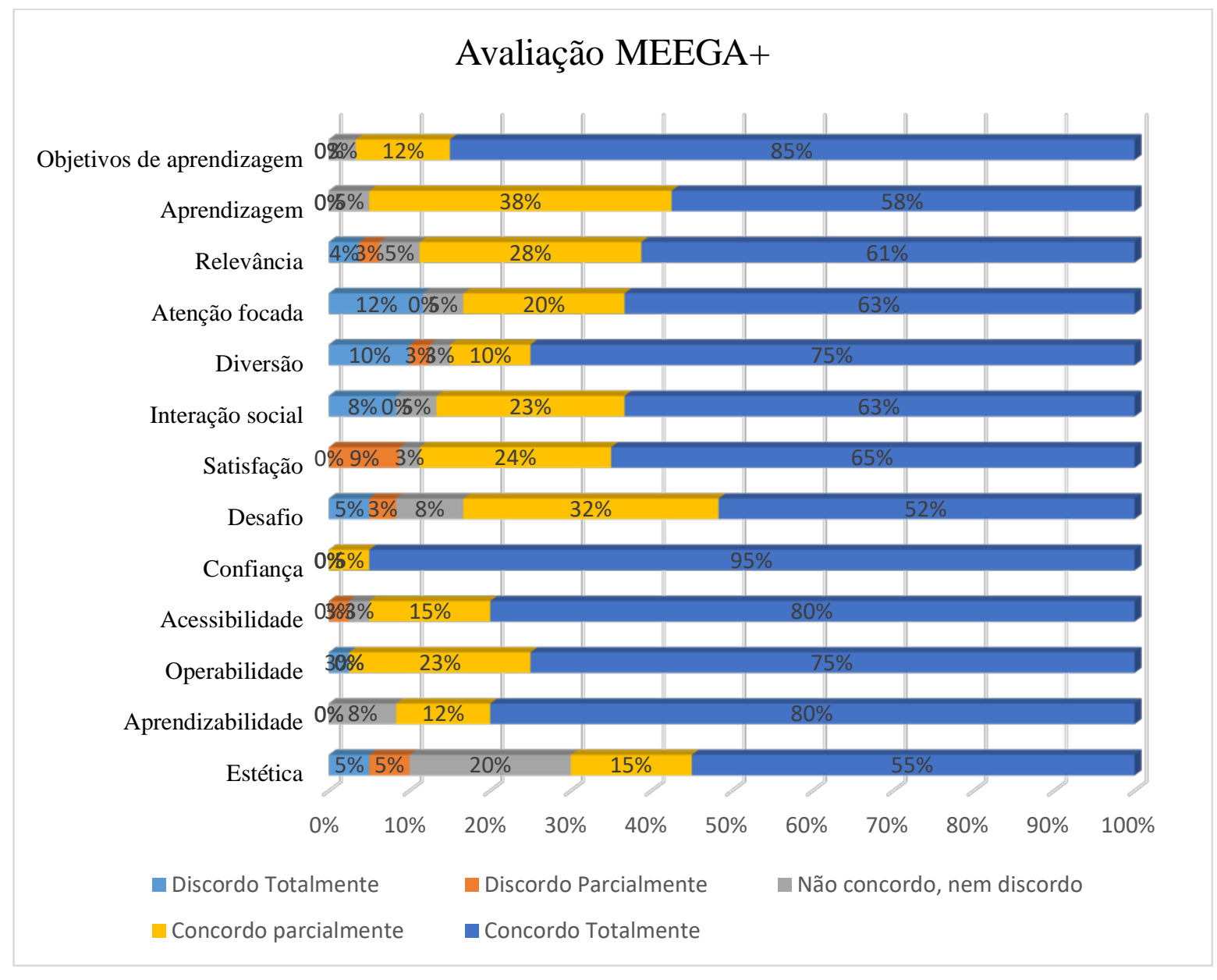

Gráfico 3: Distribuição das respostas do teste MEEGA+ considerando todos os critérios.

Ainda no Gráfico 3, quando analisada à variável aprendizagem, apesar de ter uma boa pontuação, não existem indicadores que nos permitam inferir se os resultados permaneceriam a longo prazo, ou ainda se de fato houve aprendizagem, uma vez que o teste mede a percepção do jogador em relação a uma possível contribuição para a aprendizagem. A rubrica confiança mostra uma taxa de aceitação de $95 \%$, o que se considera positivo no caso da inserção do jogo como ferramenta em sala de aula, pois não seria uma ferramenta estranha aos usuários que jogam diariamente jogos comerciais. A possibilidade de utilização da ferramenta em sala de aula é corroborada também pela rubrica aprendizibilidade e operabilidade que alcançaram taxas de aceitação de $80 \%$ e $75 \%$, respectivamente, isso indica que o público-alvo pode não ter sentido dificuldade em adaptar-se à ferramenta.

\subsection{Avaliação quanto a usabilidade}

Para verificar as características de usabilidade foi utilizado também o SUS (System Usability Scale) (Brooke, 1996). Um método de verificação do nível de usabilidade de um sistema, que pode ser usado em diferentes ferramentas e serviços, tendo perguntas abertas que são aplicáveis a várias questões. O instrumento gera uma única pontuação, o que facilita a sua compreensão e comparação entre as variáveis. A estrutura das perguntas apresenta uma alternância entre itens positivos e negativos de forma a evitar viés. O teste é composto por dez questões que são divididas em subconjuntos para avaliar diferentes aspectos, entre eles, a facilidade de aprendizagem, a eficiência, a facilidade de memorização, a minimização de erros e a satisfação. O teste apresenta 
uma escala com seis valores, embora sua aplicação use a escala Likert com cinco valores, com isto, a escala SUS tem os seguintes valores: 20,5 pior imaginável; de 21 a 38,5 pobre; de 39 a 52,5 mediano; de 53 a 73,5 bom; de 74 a 85,5 excelente; e de 86 a 100 melhor imaginável.

Para medir a usabilidade do jogo utilizando o SUS foi selecionado um grupo de professores e alunos da área de Computação, em um espaço amostral de $n=19$, todos pertencentes a uma universidade pública. O grupo era composto por $70 \%$ de pessoas do sexo masculino e $30 \%$ do sexo feminino. Cada participante teve 30 minutos para jogar e, após este tempo, foi disponibilizado o link para que o participante respondesse o questionário.

O teste apresentou uma média de pontuação de 68,8, sendo o maior 92,5 e o menor 25, com uma taxa de variação de 67,5. O que significa que embora a pontuação indique que o software foi classificado como "bom”, algumas mudanças ainda são necessárias, especialmente na adequação do manual do jogo, uma vez que algumas pessoas apresentaram dificuldades para reconhecer os controles utilizados no teclado.

A escolha deste público, para este teste, se deu por eles terem afinidade com tecnologia e o principal objetivo foi avaliar a experiência do usuário através da percepção da usabilidade do sistema. Como resultado, percebeu-se que, ao contrário dos testes realizado pelo público-alvo utilizando o teste MEEGA+, este público se ateve a avaliar a usabilidade de uma ferramenta computacional, não vendo o jogo como uma oportunidade de aprendizagem. Na sessão de usabilidade do MEEGA+ a pontuação adquirida, representada pela composição dos critérios Estética, Aprendizibilidade, Operabilidade, foi de 87\% entre 4 e 5 bom e ótimo (escala Likert), 9\% neutro e $3 \%$ entre os números 1 e 2 . O objetivo de aplicar essa avaliação com pessoas que têm conhecimento sobre requisitos de Interação Humano-Computador, foi verificar a diferença entre a visão dos estudantes que são o público-alvo da ferramenta e pessoas relacionadas à Computação, sejam profissionais ou estudantes de Computação.

\section{Considerações Finais}

Muitas pesquisas vêm sendo realizadas tanto no que diz respeito a melhorar processos de aprendizagem quanto sobre como os jogos podem ser importantes aliados nesse contexto. O grande desafio é projetar jogos capazes de promover a aprendizagem de maneira engajadora e para os pesquisadores da área um grande desafio é criar serious games educacionais de fato divertidos e imersivos.

Este trabalho tem como objetivo apresentar o desenvolvimento do jogo intitulado "O Livro do Conhecimento”, que pode ser utilizado como ferramenta de auxílio à aprendizagem em Língua Portuguesa. O jogador é motivado a vencer os desafios, gradativamente, em cada etapa, dentro do processo de construção do conhecimento proporcionado pelo ambiente. Durante o percurso do jogo surgem desafios que buscam estimular o jogador a superá-los, tais desafios trazem questões sobre a ortografia de algumas palavras. O jogo alterna entre apresentar palavras com a grafia correta e incorreta e o jogador avança conforme vai respondendo as questões de forma correta. $\mathrm{O}$ ciclo de aprendizagem foi desenhado de acordo com a jornada do herói, no caso desempenhada pela princesa Diana. Um dos destaques do jogo é o protagonismo ser exercido por uma personagem feminina, princesa e guerreira.

O jogo foi projetado para respeitar os princípios cognitivos apoiados pela Neurociência ao fazer uso da Teoria da Carga Cognitiva e Aprendizagem Multimídia. Durante a trama do jogo, o percurso de aprendizagem é traçado pelas tarefas de pular um obstáculo e liberar uma parte do trajeto, através de escolhas de palavras ou ainda captura de pergaminhos com informações. Em todo o cenário são dispostos elementos que podem gerar aprendizagem por meio de palavras, sons 
e imagens, gerando também envolvimento emocional através do enlace de pensamentos e lembranças, oriundos das experiências vividas no decorrer do jogo.

Foram realizadas avaliações do jogo durante as etapas de desenvolvimento da ferramenta até que ele estivesse em condições de ser verificado pelo público-alvo. Foram realizados três processos de avaliação: i) fluxo de jogo e aprendizagem (protótipo 1) em que a proposta foi realizada junto ao professor (designer instrucional), ii) Teoria de Aprendizagem Multimídia, e adequação ao design de aprendizagem (protótipo 2), realizada pelos desenvolvedores acompanhados do designer instrucional, iii) usabilidade, jogabilidade, engajamento e percepção de aprendizagem, realizado com pessoas externas ao desenvolvimento (estudantes de Ensino Médio, professores e estudantes de Computação) e testes de interface e funcional realizados na versão digital. Todos os testes realizados apontam um promissor desempenho da ferramenta, com necessidade de ajustes, especialmente em relação à usabilidade. Em se tratando de uma alternativa lúdica para aprendizagem, o Livro do Conhecimento foi bem recebido pelos alunos que informaram gostar mais de aprender com o jogo do que com os livros em sala de aula e gostariam que o jogo tivesse mais conteúdo, mais fases pois assim poderiam aprender mais coisas. Um fator interessante é que durante as avaliações todos os estudantes e professores informaram ter experiência em jogos, informação que fortalece a ideia de usar jogos em sala de aula. O jogo é uma versão experimental e conta com três conteúdos curriculares do Ensino Médio, tais como: uso dos porquês, escrita correta de palavras (fonologia de palavras empregando x e ch, z, s ou x, etc) e uso de "mas e mais".

O trabalho abriu algumas possibilidades quanto aos processos construtivos de serious games educacionais através da proposta de um jogo de aventura com mecânicas e gameplay semelhantes a grandes sucessos com Super Mario World e CupHead.

Como trabalhos futuros, pretende-se aumentar o número de fases do jogo de acordo com uma sequência didática curricular em ortografia e gramática da Língua Portuguesa, em seguida realizar testes com maior unidade amostral e disponibilizar gratuitamente a nova versão do jogo, para que possa ser usado nas escolas ou em casa, como reforço escolar.

\section{Referências}

Abt, C. C. (1987). Serious games. University press of America. [GS Search]

Ang, C. S., Zaphiris, P., \& Mahmood, S. (2007). A model of cognitive loads in massively multiplayer online role playing games. Interacting with computers, 19(2), 167-179. DOI: https://doi.org/10.1016/j.intcom.2006.08.006 [GS Search]

Araújo, N. M. S., \& Freitas, F. R. R. (2017). Pedagogic software evaluation protocol: analyzing a digital educational game for portuguese language teaching. Alfa: Revista de Linguística (São José do Rio Preto), 61(2), 381-408. DOI: http://dx.doi.org/10.1590/1981-5794-1709$\underline{6}$ [GS Search]

Assis, L., Bodolay, A., Gregório, L., Santos, M., Vivas, A., Pitangui, C., \& Bandeira, D. (2017, October). Grapphia: Aplicativo para dispositivos móveis para auxiliar o ensino da ortografia. In Anais dos Workshops do Congresso Brasileiro de Informática na Educação (Vol. 6, No. 1, p. 609). DOI: http://dx.doi.org/10.5753/cbie.wcbie.2017.609 [GS Search]

Barboza Jr, A. T., \& Silveira, I. F. (2015, October). Brincando com as Letras: Um serious game para o ensino do Alfabeto. In Anais dos Workshops do Congresso Brasileiro de Informática na Educação (Vol. 4, No. 1, p. 377). DOI: http://dx.doi.org/10.5753/cbie.wcbie.2015.377 [GS Search] 
Bellotti, F., Kapralos, B., Lee, K., Moreno-Ger, P., \& Berta, R. (2013). Assessment in and of serious games: an overview. Advances in Human-Computer Interaction, 2013, 1. DOI: https://doi.org/10.1155/2013/136864 [GS Search]

Brooke, J. (1996). SUS-A quick and dirty usability scale. Usability evaluation in industry, 189(194), 4-7. [GS Search]

Carr, N. (2011). The shallows: What the Internet is doing to our brains. WW Norton \& Company. [GS Search]

Carraher, T. N. (1985). Explorações sobre o desenvolvimento da competência em ortografia em português. Psicologia: teoria e pesquisa, 1(3), 269-285. [GS Search]

Clark, J. M., \& Paivio, A. (1991). Dual coding theory and education. Educational psychology review, 3(3), 149-210. DOI: https://doi.org/10.1007/BF01320076 [GS Search]

Dehaene, S. (2012). Os neurônios da leitura. Porto Alegre: Penso. [GS Search]

Doove, L. L., Bul, K. C., Franken, I. H., Van der Oord, S., Kato, P. M., \& Maras, A. (2018). A serious game for children with Attention Deficit Hyperactivity Disorder: Who benefits the most?. PloS one, 13(3), e0193681. DOI: https://doi.org/10.1371/journal.pone.0193681 [GS Search]

Faria, M. J., \& Colpani, R. (2017). Joy e as Letrinhas: um Serious Game como ferramenta de auxílio no processo de alfabetização de crianças do ensino fundamental. Revista Brasileira de Informática na Educação, 25(2), 61. DOI: http://dx.doi.org/10.5753/rbie.2017.25.02.61 [GS Search]

Feinberg, S., \& Murphy, M. (2000, September). Applying cognitive load theory to the design of web-based instruction. In Proceedings of IEEE professional communication society international professional communication conference and Proceedings of the 18th annual ACM international conference on Computer documentation: technology \& teamwork (pp. 353-360). IEEE Educational Activities Department. [GS Search]

Gee, J. P. (2003). What video games have to teach us about learning and literacy. Computers in Entertainment (CIE), 1(1), 20-20. DOI: https://doi.org/10.1145/950566.950595 [GS Search]

Gurgel, I., Arcoverde, R. L., Almeida, E. W., Sultanum, N. B., \& Tedesco, P. (2006). A importância de avaliar a usabilidade dos jogos: a experiência do Virtual Team. Anais do SBGames, Recife. [GS Search]

Hainey, T., Connolly, T. M., Boyle, E. A., Wilson, A., \& Razak, A. (2016). A systematic literature review of games-based learning empirical evidence in primary education. Computers \& Education, 102, 202-223. DOI: https://doi.org/10.1016/j.compedu.2016.09.001 [GS Search]

Huizinga, J. (1971). Homo ludens: o jogo como elemento da cultura (Vol. 4). Editora da Universidade de S. Paulo, Editora Perspectiva. [GS Search]

INEP. (2016). Resultados da ANA 2016 por estados e municípios estão disponíveis no Painel Educacional do Inep. It is available for free at: http://portal.inep.gov.br/artigo/lasset_publisher/B4AQV9zFY7Bv/content/resultados-da-ana-2016-por-estados-emunicipios-estao-disponiveis-no-painel-educacional-do-inep/21206

ISO/IEC. (2014). ISO/IEC 2510: Systems and software engineering - Systems and software Quality Requirements and Evaluation (SQuaRE) - System and software quality models.

Kafai, Y. B., \& Burke, Q. (2015). Constructionist gaming: Understanding the benefits of making 
games for learning. Educational psychologist, 50(4), 313-334. DOI: https://doi.org/10.1080/00461520.2015.1124022 [GS Search]

Klopfer, E., Haas, J., Osterweil, S., \& Rosenheck, L. (2018). Resonant Games: Design Principles for Learning Games that Connect Hearts, Minds, and the Everyday. MIT Press. [GS Search]

Lavie, N. (2005). Distracted and confused?: Selective attention under load. Trends in cognitive sciences, 9(2), 75-82. DOI: https://doi.org/10.1016/j.tics.2004.12.004 [GS Search]

Lorensatti, E. J. C. (2009). Linguagem matemática e Língua Portuguesa: diálogo necessário na resolução de problemas matemáticos. Conjectura: Filosofia e Educação, 14(2). [GS Search]

Lugmayr, A., Sutinen, E., Suhonen, J., Sedano, C. I., Hlavacs, H., eMontero, C. S. (2017). Serious storytelling-a first definition and review. Multimedia Tools and Applications, 76(14), 15707-15733. DOI: https://doi.org/10.1007/s11042-016-3865-5 [GS Search]

Matias, A. C., Amadora, A. J., Aquino, K. N., Choy, M. S., Cabredo, R. (2018). Evaluating RoboKuma: A Serious Game to Measure Cognitive Abilities. Paper presented at the Theory And Practice Of Computation-Proceedings Of Workshop On Computation: Theory And Practice Wctp2017. DOI: https://doi.org/10.1142/9789813279674_0016 [GS Search]

Mayer, R. E. (2009). Multimedia Learning. In Cambridge (Series Ed.) Vol. 1. Cambridge (Ed.) doi:doi:10.1017/CBO9780511811678 [GS Search]

McGonigal, J. (2017). A realidade em jogo. São Cristovão - Rio de Janeiro - RJ: Editora Best Seller. [GS Search]

Michael, D. R., Chen, S. L. (2005). Serious games: Games that educate, train, and inform: Muska \& Lipman/Premier-Trade. [GS Search]

Miller, G. (1956). The magical number seven, plus or minus two: Some limits on our capacity for processing information. Psychological review, 63(2), 81. DOI: https://doi.org/10.1037/h0043158 [GS Search]

Mitchell, A., Savill-Smith, C. (2004). The use of computer and video games for learning: A review of the literature. [GS Search]

Oliveira, A. C. C., Castro, M. d. G. A., Ferreira, L. D. S., e Ouverney-King, J. (2017). Superhífen: gamifying the hyphen. Paper presented at the Brazilian Symposium on Computers in Education (Simpósio Brasileiro de Informática na Educação-SBIE). DOI: http://dx.doi.org/10.5753/cbie.sbie.2017.564 [GS Search]

Oliveira, A. M., Carvalho, R., Cunha, I., Maia, D. (2017). Letra Livre 2.0: um software educativo livre para o letramento. Paper presented at the Anais dos Workshops do Congresso Brasileiro de Informática na Educação. http://dx.doi.org/10.5753/cbie.wcbie.2017.184 [GS Search]

Padilla-Zea, N., Gutiérrez, F. L., López-Arcos, J. R., Abad-Arranz, A., ePaderewski, P. J. C. i. H. B. (2014). Modeling storytelling to be used in educational video games. 31, 461-474. DOI: https://doi.org/10.1016/j.chb.2013.04.020 [GS Search]

Petri, G., von Wangenheim, C. G., Borgatto, A. F. J. I. G. (2016). MEEGA+: an evolution of a model for the evaluation of educational games. 3. [GS Search]

Pires, F., Michel, F., Bernardo, J., Melo, R., Freitas, R. (2018). O livro do conhecimento: Um jogo de aventura para exercitar a ortografia. Paper presented at the Brazilian Symposium on Computers in Education (Simpósio Brasileiro de Informática na Educação-SBIE). [GS Search] 
Pires, F., Silva , J., Pessoa, M., Melo, R. (2018). A Viagem: Um jogo para explorar o território Brasileiro. Paper presented at the Brazilian Symposium on Computers in Education (Simpósio Brasileiro de Informática na Educação-SBIE). DOI: http://dx.doi.org/10.5753/cbie.sbie.2018.705 [GS Search]

Price, S., Duffy, S., eGori, M. (2017). Developing a pedagogical framework for designing a multisensory serious gaming environment. Paper presented at the Proceedings of the 1 st ACM SIGCHI International Workshop on Multimodal Interaction for Education. DOI: https://doi.org/10.1145/3139513.3139517 [GS Search]

Rogers, S. (2014). Level Up! The Guide to Great Video Game Design: Wiley. [GS Search]

Rosenheck, L., Gordon-Messer, S., Clarke-Midura, J., teneKlopfer, E. (2016). Design and Implementation of an MMO: approaches to support inquiry learning with games Handbook of Research on Gaming Trends in P-12 Education (pp. 33-54): IGI Global. DOI: 10.4018 / 978-1-4666-9629-7.ch002 [GS Search]

Slimani, A., Sbert, M., Boada, I., Elouaai, F., eBouhorma, M. (2016). Improving Serious Game Design Through a Descriptive Classification: a Comparation of Methodologies. Journal of Theoretical and Applied Information Technology, 2016, vol. 92, núm. 1, 130-143. [GS Search]

Subrahmanyam, K., eRenukarya, B. (2015). Digital games and learning: Identifying pathways of influence. Educational psychologist, 50(4), 335-348. DOI: https://doi.org/10.1080/00461520.2015.1122532 [GS Search]

Susi, T., Johannesson, M., eBacklund, P. (2007). Serious games: An overview: Institutionen för kommunikation och information. [GS Search]

Sweetser, P., eWyeth, P. (2005). GameFlow: a model for evaluating player enjoyment in games. Computers in Entertainment (CIE), 3(3), 3-3. DOI: https://doi.org/10.1145/1077246.1077253 [GS Search]

Sweller, J. (1994). Cognitive load theory, learning difficulty, and instructional design. 4(4), 295312. DOI: https://doi.org/10.1016/0959-4752(94)90003-5 [GS Search]

Sweller, J. (2011). Cognitive load theory Psychology of learning and motivation (Vol. 55, pp. 3776): Elsevier. DOI: https://doi.org/10.1016/B978-0-12-387691-1.00002-8 [GS Search]

Yamato, E. M., Corrêa, A. G. D., eMartins, V. F. (2017). AmarganA: A spelling game of the Portuguese language for use in mobile devices. Paper presented at the 12th Iberian Conference on Information Systems and Technologies (CISTI). DOI: 10.23919/CISTI.2017.7975675 [GS Search]

Zemor, M. F., Santos, A. V., Sprock, A. S., eViccari, R. (2015). CARNAVAL: masCote para o ApReNdizAdo VirtuAl de Língua portuguesa. Paper presented at the Anais dos Workshops do Congresso Brasileiro de Informática na Educação. DOI: http://dx.doi.org/10.5753/cbie.wcbie.2015.778 [GS Search]

Zyda, M. J. C. (2005). From visual simulation to virtual reality to games. 38(9), 25-32. [GS Search] 